\title{
Characterization and properties of micro- and nanowires of controlled size, composition, and geometry fabricated by electrodeposition and ion-track technology
}

Maria Eugenia Toimil-Molares

\section{Review}

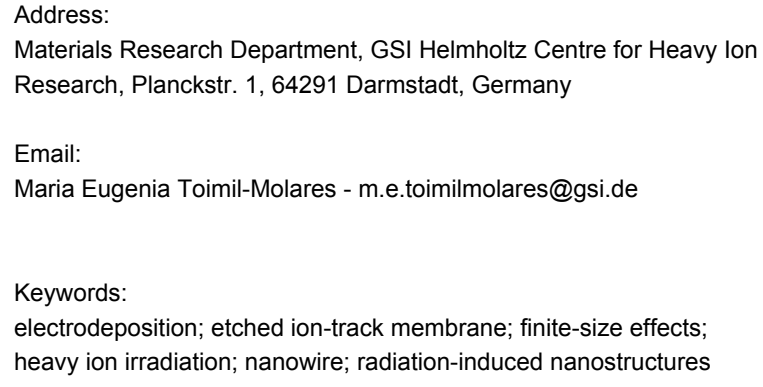

Materials Research Department, GSI Helmholtz Centre for Heavy lon

Research, Planckstr. 1, 64291 Darmstadt, Germany

Email:

Maria Eugenia Toimil-Molares - m.e.toimilmolares@gsi.de

Keywords:

electrodeposition; etched ion-track membrane; finite-size effects; heavy ion irradiation; nanowire; radiation-induced nanostructures

\author{
Beilstein J. Nanotechnol. 2012, 3, 860-883. \\ doi:10.3762/bjnano.3.97 \\ Received: 13 July 2012 \\ Accepted: 19 November 2012 \\ Published: 17 December 2012 \\ This article is part of the Thematic Series "Radiation-induced \\ nanostructures: Formation processes and applications". \\ Guest Editor: M. Huth
}

(C) 2012 Toimil-Molares; licensee Beilstein-Institut.

License and terms: see end of document.

\begin{abstract}
The combination of electrodeposition and polymeric templates created by heavy-ion irradiation followed by chemical track etching provides a large variety of poly- and single-crystalline nanowires of controlled size, geometry, composition, and surface morphology. Recent results obtained by our group on the fabrication, characterization and size-dependent properties of nanowires synthesized by this technique are reviewed, including investigations on electrical resistivity, surface plasmon resonances, and thermal instability.
\end{abstract}

\section{Introduction}

During the past decade, nanowires have attracted an enormous interest due to a large variety of promising applications in areas such as nanoelectronics, biotechnology, magnetism, thermoelectrics, solar cells, and water splitting, among others [1-4]. Their reduced size, elongated geometry, and high surface-tovolume ratio turn nanowires into ideal elements for electrical and electrochemical systems $[5,6]$. In addition, nanowires are considered excellent model objects to study how fundamental physical properties (such as mechanical, optical, electronic, thermoelectrical and magnetic) depend on dimension, composition, geometry and crystallinity of the nanostructures [7-9]. The investigation of size effects requires methods to synthesize nanowires under controlled conditions and with tailored characteristics. Moreover, to characterize physical and chemical properties at the single-nanowire level requires appropriate techniques. In the two areas of fabrication and characterization, 
great advances have been reported in recent years. Methods to fabricate nanowires include top-down approaches such as optical and electron-beam lithography, and focused ion beam. More commonly applied bottom-up approaches are, e.g., vapour-liquid-solid growth, sol-gel and other chemical methods $[10,11]$. This review focuses on the bottom-up template method, which provides nanowires of a great variety of materials, from metals to semiconductors, including polymers as well as inorganic and organic compounds [12]. The material of interest is synthesized in the channels or cavities of the given template. During growth, the nanostructures adopt the exact shape and size of the hosting channels [13]. The most commonly used templates are porous alumina [14], diblockcopolymers [15], and track-etched membranes. Electrochemical and electroless deposition, polymerisation reactions, sol-gel template synthesis, and high-pressure injection of a melted material are examples of available techniques suitable for filling the pores. The electrodeposition of $40 \mathrm{~nm}$ diameter metal nanowires ( $\mathrm{Sn}, \mathrm{In}$, and $\mathrm{Zn}$ ) in etched fission tracks in mica was reported by Possin et al. back in 1970 [16]. In 1984, Williams and Giordano employed the same method to synthesize nanowires with a diameter as small as $10 \mathrm{~nm}$ using mica templates [17]. Since then, a large variety of materials have been electrodeposited, mainly in polymeric etched ion-track membranes [18-24]. Advantages of the electrodeposition method include low fabrication cost, high deposition rates, and its suitability for filling low- and high-aspect-ratio pores and trenches [25]. The wires are grown from the bottom to the top, yielding homogeneous replication of channels with any given geometry [26]. All relevant parameters, such as wire diameter, wire density, geometry, material and crystallinity, can be adjusted, allowing systematic studies of finite- and quantumsize effects on wire properties relevant for various technological applications.

This paper reviews recent advances in the electrodeposition of metal, semimetal, and semiconductor nanowires in polymeric etched ion-track membranes. Particular focus is given to our current efforts to study the influence of size, morphology and crystallinity of nanowires on electrical, optical and thermal properties. In section 1, we discuss the processes involved in the fabrication of etched ion-track membranes and electrodeposition of nanowires. Section 2 includes results on the compositional and crystallographic characterization of nanowires of various materials including metals, semimetals and semiconductors. The different nanowire morphologies attained by deposition in etched ion-track membranes are summarized in section 3. Finally, in section 4, recent results obtained by our group on electrical, optical, and thermal size-effects of the electrodeposited nanowires are presented.

\section{Review}

\section{Nanowire fabrication}

\subsection{Fabrication of etched ion-track membranes}

In the past two decades, etched ion-track membranes have been widely used as templates for the creation of nanowires and nanotubes. Their fabrication involves two separate processing steps: (i) Irradiation of the template material with energetic heavy ions and creation of latent tracks; (ii) selective ion-track dissolution and formation of channels by chemical etching. Control over the irradiation and etching conditions enables the production of various membranes with channels of predefined geometries, sizes and aspect ratios.

1.1.1 Swift heavy-ion irradiation: Swift heavy-ion beams are provided at large accelerator facilities, such as the linear accelerator of GSI (Darmstadt, Germany), and the cyclotrons at GANIL (Caen, France), JINR (Dubna, Russia), and CICLONE (Louvain la Neuve, Belgium) and a few others outside Europe, for example in Lanzhou (China) and Brookhaven (USA). The UNILAC linear accelerator of GSI provides heavy ions (up to uranium) of specific energy up to $11.4 \mathrm{MeV}$ per nucleon ( $\mathrm{MeV} / \mathrm{u}$ ) corresponding to $\approx 15 \%$ of the velocity of light [27]. Ion beams of such high energy have a penetration range in polymers of about $120 \mu \mathrm{m}$. Given this large range, foil stacks (e.g., ten foils $12 \mu \mathrm{m}$ thick, or four foils $30 \mu \mathrm{m}$ thick) can be irradiated. Each ionic projectile induces electronic excitation and ionisation processes in a cylindrical zone along its trajectory. In polymers, chemical bonds are destroyed and small volatile fragments (e.g., $\mathrm{H}_{2}, \mathrm{CO}, \mathrm{CO}_{2}$, hydrocarbons) easily outgas [28]. This damaged region is called the ion track and has a typical diameter of few nanometres.

By suitable adjustment of the ion beam and monitoring the flux (beam current), the applied ion fluence can be adjusted over a wide range, from exposure to a single ion (single track) up to more than $10^{12}$ ions $/ \mathrm{cm}^{2}$ (overlapping tracks) (Figure 1a). At the UNILAC beamline of the GSI facilities, irradiation with a broad homogenous beam is obtained by magnetic defocusing. Samples of up to several square centimetres in size can be exposed. The resulting ion tracks are stochastically distributed and oriented in parallel across the sample. Irradiation with one single ion requires monitoring of individual ions hitting the sample [29]. To achieve this, the sample is irradiated through a small circular aperture (diameter $\approx 200 \mu \mathrm{m}$ ) placed in front of a stack of foils. The ion beam is strongly defocused and adjusted in such a way that single projectiles pass through the aperture with a frequency of about $1 \mathrm{~Hz}$. The ions are detected by a solid-state particle detector placed behind the sample. As soon as the detector has registered a single ion impact, the entire ion beam is deflected by an electrostatic chopper system. A schematic representation of the single-ion irradiation system is 
(a)

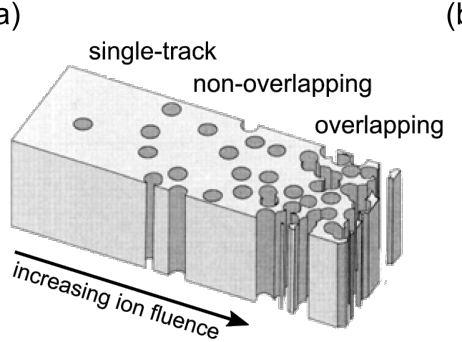

(b)

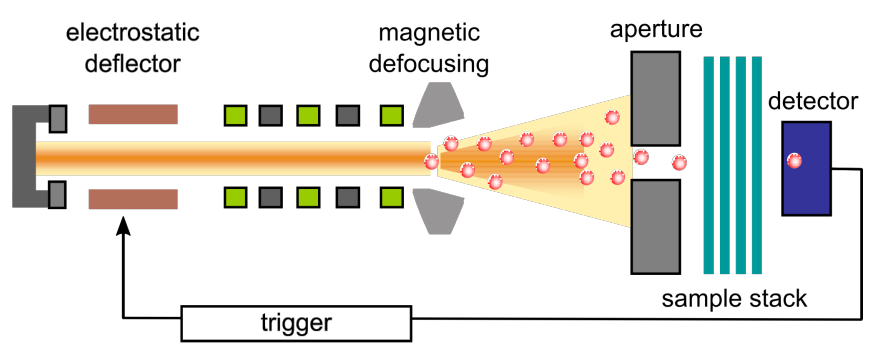

Figure 1: (a) Track-etched membrane illustrating the porosity regime available by means of ion-track technology: single channel, non-overlapping channels, and overlapping channels. (b) Schematic of single-ion irradiation setup.

presented in Figure 1b. This GSI single-ion irradiation facility is routinely used for the production of single-nanopore membranes [30-33] and the growth of single nanowires [34-36]. If required for specific applications, it is possible to create a preset regular ion-track arrangement by using a microprobe [37]. Materials commonly used as multi- and single-pore etched-ion-track membranes include polymers such as polyimide (PI), polyethylene terephthalate (PET) and polycarbonate (PC), and inorganic materials such as mica and glass.

The production of membranes with open channels requires selective dissolution of the latent tracks (cf. subsection 1.1.2). Selective track etching of channels with small size distributions requires continuous and homogeneous damage along the ion trajectory. Best results are achieved when the energy loss of the ions in the given material is above the so-called etching threshold [38]. Figure 2a presents the energy loss of light- and heavy-ion projectiles in polyimide. The different symbols denote cylindrical (full), discontinuous (crossed), and spherical (open) damage morphology with respective homogenous (full), inhomogeneous (crossed), and missing (open) selective track etching. Scanning electron microscopy (SEM) images in Figure $2 \mathrm{~b}$ reveal how the etching of homogeneous tracks results in channels of uniform size (top) after etching tracks of homogeneous damage, whereas etching of inhomogeneous tracks leads to pores with a broad size distribution (bottom) [38]. Heavier projectiles (e.g., $\mathrm{Au}, \mathrm{Pb}, \mathrm{Bi}, \mathrm{U}$ ), produce tracks of more pronounced and continuous damage and are thus optimal for the production of porous membranes with small pore size distributions.

1.1.2. Chemical etching: In a suitable etching solution the ion tracks can be selectively dissolved and subsequently enlarged into channels [39]. For the successful fabrication of templates, the anisotropic dissolution rate along the ion track $\left(V_{\mathrm{t}}\right)$ must be higher than the dissolution rate of the undamaged bulk material $\left(V_{\mathrm{b}}\right)$. The material of choice together with the etching conditions (temperature, composition, and concentration of the etchant) determine the track-to-bulk etching ratio $\left(V_{\mathrm{t}} / V_{\mathrm{b}}\right)$ and thus also the geometry of the channels. High $V_{\mathrm{t}} / V_{\mathrm{b}}$ ratios result (a)

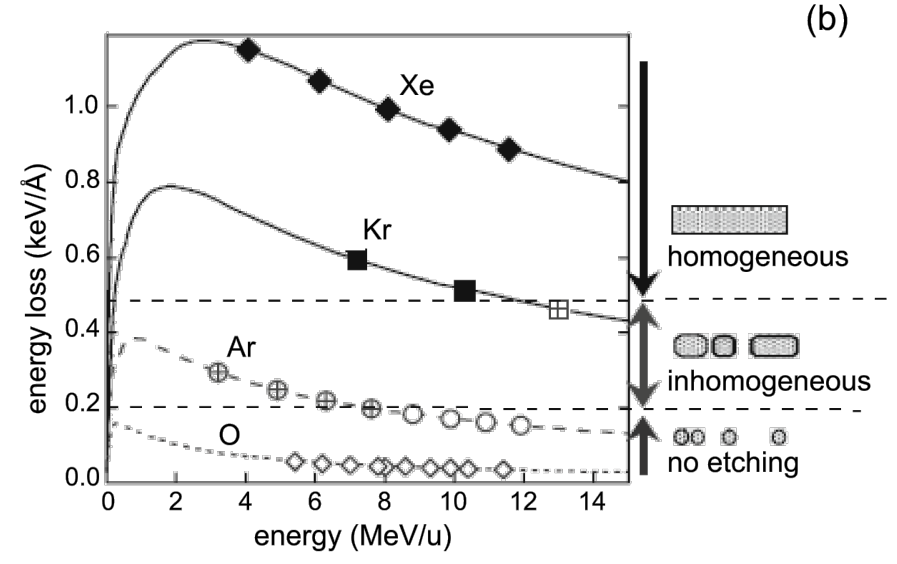

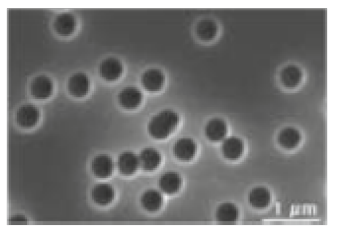

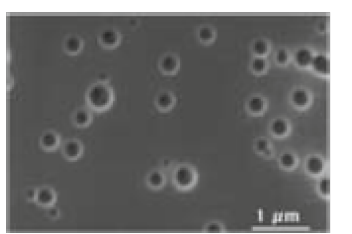

Figure 2: (a) Energy loss as a function of specific ion energy. The dashed lines separate the different regimes of track etching: homogenous (full symbols), inhomogeneous (crossed symbols), and absence of etching (open). (b) SEM images of uniform pores resulting from homogeneous tracks (top) and pores with broad size distribution due to inhomogeneous tracks (bottom). Adapted with permission from [38] - Copyright 1996 Elsevier. 


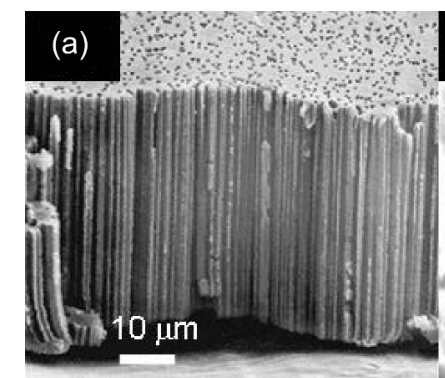

cylindrical

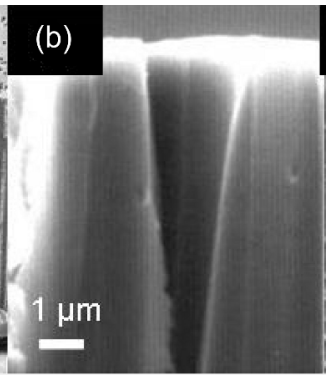

conical

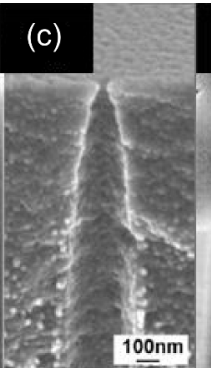

cigar-shaped

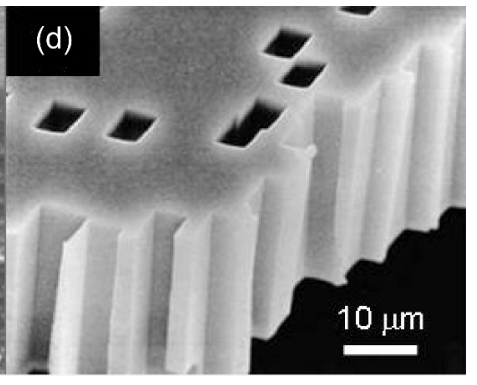

rhombohedral cross section

Figure 3: SEM images displaying the cross sections of the following membranes: (a) cylindrical channels in PI; (b) conical channels in PI; (c) cigarshaped channels in PET, (d) cylindrical channels with rhombohedral cross section in mica. (a,b) Adapted with permission from [26] - Copyright 1996 Elsevier; (c) adapted with permission from [42] - Copyright 2007 IOP Publishing Ltd; (d) adapted with permission from [43] - Copyright 2012 American Physical Society.

in the formation of cylindrical channels (Figure $3 \mathrm{a}$ and Figure 3d), whereas low ratios result in conical (Figure $3 b$ ) or biconical channels. High etching selectivity is achieved in PI by using, e.g., sodium hypochlorite $(\mathrm{NaOCl})$ [26], while tracks in PET and PC are preferentially etched in sodium hydroxide $(\mathrm{NaOH})$ solutions [34,39]. Exposure of ion-irradiated polymers to UV light prior to etching increases $V_{\mathrm{t}}$ and leads to a narrower size distribution of the channels $[40,41]$.

Symmetric etching of cylindrical channels is performed in a thermostated etching bath (Figure 4a). Stirring improves convection and provides a homogeneous temperature of the bath. Alternatively, chemical etching in both symmetric and asymmetric configuration can be performed in a two-compartment electrolytical cell at constant temperature (Figure $4 \mathrm{~b}$ and Figure $4 \mathrm{c}$ ). The irradiated foil is sealed between the two halfcells. Exposing the foil surfaces to different solutions (e.g., etching and neutralizing agents), allows one to adjust different conditions. By means of current measurements, the etching process is monitored online. A voltage $U$ is applied between two gold electrodes immersed at each side of the foil and the current $I$ is recorded with a picoammeter as a function of time. While the pore has not yet been etched through, the membrane acts as a very large resistance, and no current flows. As soon as the track is converted into an open channel, the electric current $I$ starts to increase. The etching is continued and the current will increase as the pore diameter enlarges [31].

For the fabrication of cylindrical multi- or single pores in PC, the etching process is performed in a symmetric configuration by exposing the foil to concentrated $\mathrm{NaOH}$ solution on both membrane sides (Figure 4b) $[34,44,45]$. To obtain conical nanopores, one half-cell is filled with a suitable etchant while the other half-cell contains either water or an acidic stopping medium that neutralizes the etchant as soon as the pore opens. In both cases, further etching is extensively slowed down or entirely stopped (Figure 4c). In addition, by immersing the positive anode in the etching solution, the negative ions in the (a)

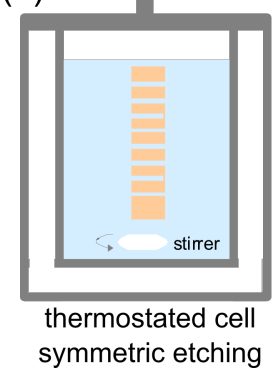

(b)

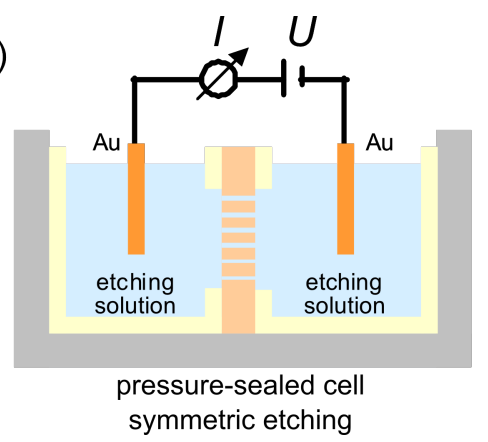

(c)

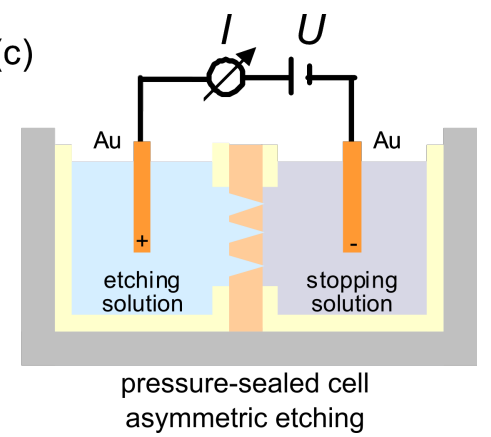

Figure 4: Schematic of etching equipment. Symmetric etching conditions leading to cylindrical channels in (a) thermostated cell and (b) pressuresealed cell. (c) Asymmetric conditions leading to conical channels in pressure-sealed cell. Electric current measurements allow monitoring of the etching process. 
etchant migrate away from the pore tip when the pore breaks through. This helps to create channels of reduced tip diameter [46].

Conical nanopores in PET, PC, and PI have been produced with different combinations of etching and stopping solutions. For example, conical channel geometries in PC and PET are typically achieved by using solutions of sodium hydroxide (various concentrations) for etching and a mixture of potassium chloride $(\mathrm{KCl})$ and formic acid $(\mathrm{HCOOH})$ for stopping $[31,46]$. Methanol can be added in different concentrations to the $\mathrm{NaOH}$ etchant to influence $V_{\mathrm{b}}$. In the case of $30 \mu \mathrm{m}$ thick PC foils, it was reported that with an increasing volume concentration of methanol from 0 to $80 \%$, the cone half-angle increases from about 0.2 to about $3.6^{\circ}$ [47]. In the case of PI, the etching is typically performed in sodium hypochlorite $(\mathrm{NaOCl})$ solution with an initial $\mathrm{pH}$ value 12.6 and an active chlorine content of $13 \%$, while $\mathrm{KI}$ acts as reducing agent for the $\mathrm{OCl}^{-}$ions of the etchant $[32,48]$. The apex angle of the conical pores in PI becomes larger by increasing the $\mathrm{pH}$ of the $\mathrm{NaOCl}$ solution [26]. Channels with specific geometries other than cylindrical or conical, for example, cigar-shaped (Figure 3c), are fabricated by applying adequate surfactants $[46,49]$. Before further processing, the template is rinsed in purified water.

Compared to other available templates, such as di-block copolymer membranes or porous alumina, etched ion-track membranes offer the powerful possibility of controlling all important parameters of the synthesized nanostructures in an independent manner: (i) The irradiation fluence determines the preset density of parallelly oriented nanochannels; (ii) By tilting the samples in the ion beam, tilted channels can be produced yielding an interconnected nanochannel network; (iii) The polymer material of choice, together with the etching conditions, determine the geometry of the channels, e.g., cylindrical, conical, and biconical; (iv) Controlled by the etching time, uniform channels can be produced with diameters from about $10 \mathrm{~nm}$ to a few micrometres.

\subsection{Electrodeposition of nanowires}

This section presents the setting for nanowire electrodeposition, and discusses the electrochemical deposition processes as analysed by chronoamperometric monitoring.

1.2.1 Electrochemical cells: The photograph in Figure 5a shows our electrochemical cell, currently in use. The polymer foil is placed between two polytetrafluorethylene compartments, and is sealed by mechanical pressure. A good sealing is essential to avoid leak currents, an important requirement when growing single nanowires. Very small currents in the picoamp range must be recorded and analysed, as demonstrated during (a)

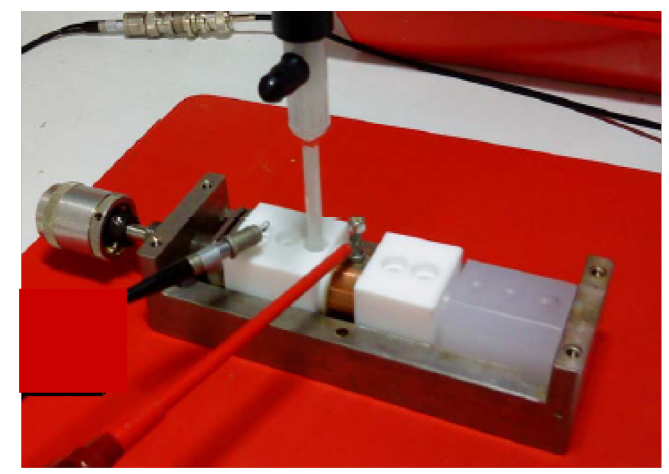

(b)

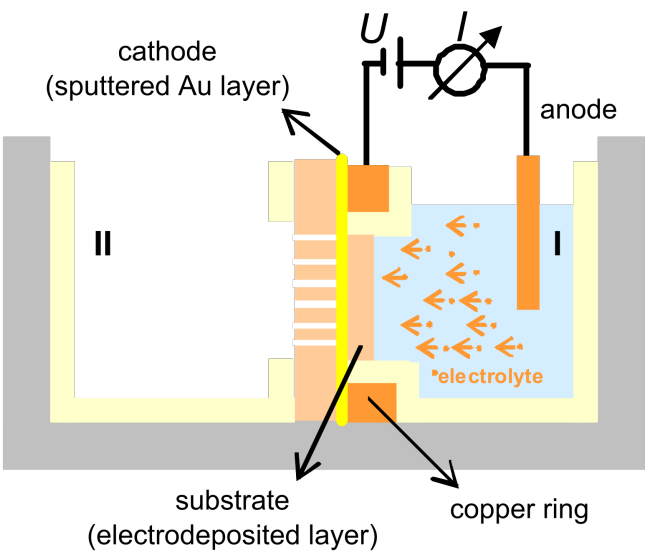

(c)

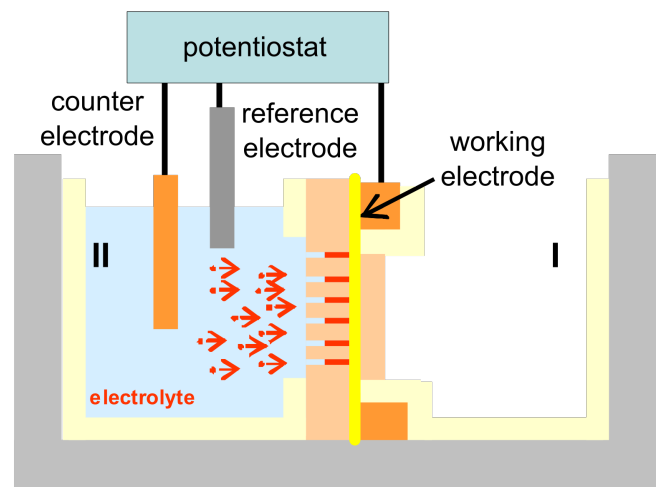

Figure 5: (a) Photograph of a pressure-sealed electrochemical cell. (b) Schematic for the electrodeposition of a conductive layer as substrate in a two-electrode configuration (cathode and anode). (c) Schematic for the growth of nanowire arrays by using three electrodes (working, counter, and reference electrode).

electrodeposition of nanowires, e.g., $\mathrm{Cu}$ and $\mathrm{Bi}$, in single-nanopore membranes $[35,36,50,51]$. This pressure-sealed cell is also suitable for the growth of nanowire arrays of various materials [52-57]. Figure 5b and Figure 5c depict schematically the two deposition processes involved in the nanowire synthesis: substrate deposition and nanowire growth, respectively. First, one side of the track-etched polymer membrane is sputter coated with a thin (few ten nanometres) Au layer. The membrane is then mounted between the two cell compartments. The sputtered metal layer is in contact with a copper ring accessible 
to external electronic equipment (voltage supply or potentiostat). In some cases, the thin conductive Au layer is reinforced electrochemically by a metal layer (e.g., $\mathrm{Cu}, \mathrm{Au}$ ) in a two electrode configuration (Figure $5 \mathrm{~b}$ ). After reinforcement, the electrolyte is removed from the first compartment (I) and the membrane is rinsed with distilled water. For the electrochemical deposition process, the specific electrolyte is introduced in the second compartment (II) and an adequate deposition potential is applied. At a preselected constant temperature, the nanowires then grow from the bottom-side (sputter-coated layer) to the top-side of the membrane (Figure $5 \mathrm{c}$ ).

The wire synthesis can be performed by using a two- or a threeelectrode arrangement, under potentiostatic or galvanostatic conditions. In the case of potentiostatic and pulsed deposition, the process is monitored by chronoamperometric current-time $(I-t)$ curves. In the two-electrode arrangement the potential $U_{\mathrm{c}}$ is applied between cathode and anode. In the three-electrode arrangement, reference electrodes such as saturated silver/silver chloride $(\mathrm{Ag} / \mathrm{AgCl} / \mathrm{sat} . \mathrm{KCl})$ and saturated calomel electrodes (SCE) are currently employed. Larger thermostated cells have also been employed, e.g., for the growth of $\mathrm{Cu}$ and $\mathrm{Bi}_{2} \mathrm{Te}_{3}$ nanowires, to improve convection by magnetic stirring or to provide temperatures above or below ambient conditions $[58,59]$.

1.2.2 Chronoamperometric monitoring: During the potentiostatic growth of nanowires, four different current regimes can be identified (Figure 6a): (1) A sharp decrease of the current at the beginning of the process attributed to the creation of the diffusion layer; (2) nanowire growth inside the channels with nearly constant current; (3) more or less sharp current increase when the material reaches the top side of the membrane and caps start to grow on top; and (4) if the process is continued, the caps grow further and eventually form a continuous layer. Current-time characteristics displaying these four distinct regions have been reported for the growth of $\mathrm{Cu}$ [52], $\mathrm{Au}$ [53], $\mathrm{Bi}$ [56], Pt [55], $\mathrm{Bi}_{1-x} \mathrm{Sb}_{x}$ [60], $\mathrm{Bi}_{2} \mathrm{Te}_{3}$ [58], and Ni nanowires among others. The integral of the $I-t$ curves between the beginning of the deposition and the transition to zone 3 corresponds to the charge $Q_{\text {exp }}$ applied during the growth process. Assuming complete pore filling, the expected total charge $Q_{\text {theo }}$ is given by the Faraday law, namely $Q_{\text {theo }}=(z \cdot F \cdot m) / M$, with $z$ being the number of electrons transferred per ion during the reaction, $F$ the Faraday constant $\left(96.485 \mathrm{C} \cdot \mathrm{mol}^{-1}\right), m$ the total mass and $M$ the molar mass of the deposited substance. In the case of $100 \%$ efficient electrochemical reactions, the ratio $Q_{\exp } / Q_{\text {theo }}$ is an indicator of the homogeneity of the wire growth over the whole sample. $Q_{\exp }<Q_{\text {theo }}$ indicates that deposition has not occurred in all channels simultaneously, and/or that the number density of the wires is lower than that of the channels. Monitoring the
$I-t$ curves during homogeneous growth allows us to stop the deposition after a given time to obtain nanowires of a predefined length. By this technique, wires of length between 1 and $60 \mu \mathrm{m}$ were fabricated. Figure $6 \mathrm{~b}$ shows representative chronoamperometric curves recorded during the potentiostatic growth of $\mathrm{Cu}$ nanowires in PC membranes $\left(d_{\text {pore }}=450 \mathrm{~nm}\right.$, $10^{7} \mathrm{~cm}^{-2}$ ) at $25^{\circ} \mathrm{C}$, in a solution consisting of $0.25 \mathrm{~mol} / \mathrm{L}$ $\mathrm{CuSO}_{4} \cdot 5 \mathrm{H}_{2} \mathrm{O}$ and $2 \mathrm{~mol} / \mathrm{L} \mathrm{H}_{2} \mathrm{SO}_{4}$, by applying different potentials ranging between -80 and $-440 \mathrm{mV}$ (versus $\mathrm{Ag} / \mathrm{AgCl} /$ $3 \mathrm{~mol} / \mathrm{L} \mathrm{KCl}$ provided with a Haber-Luggin capillary) [59].
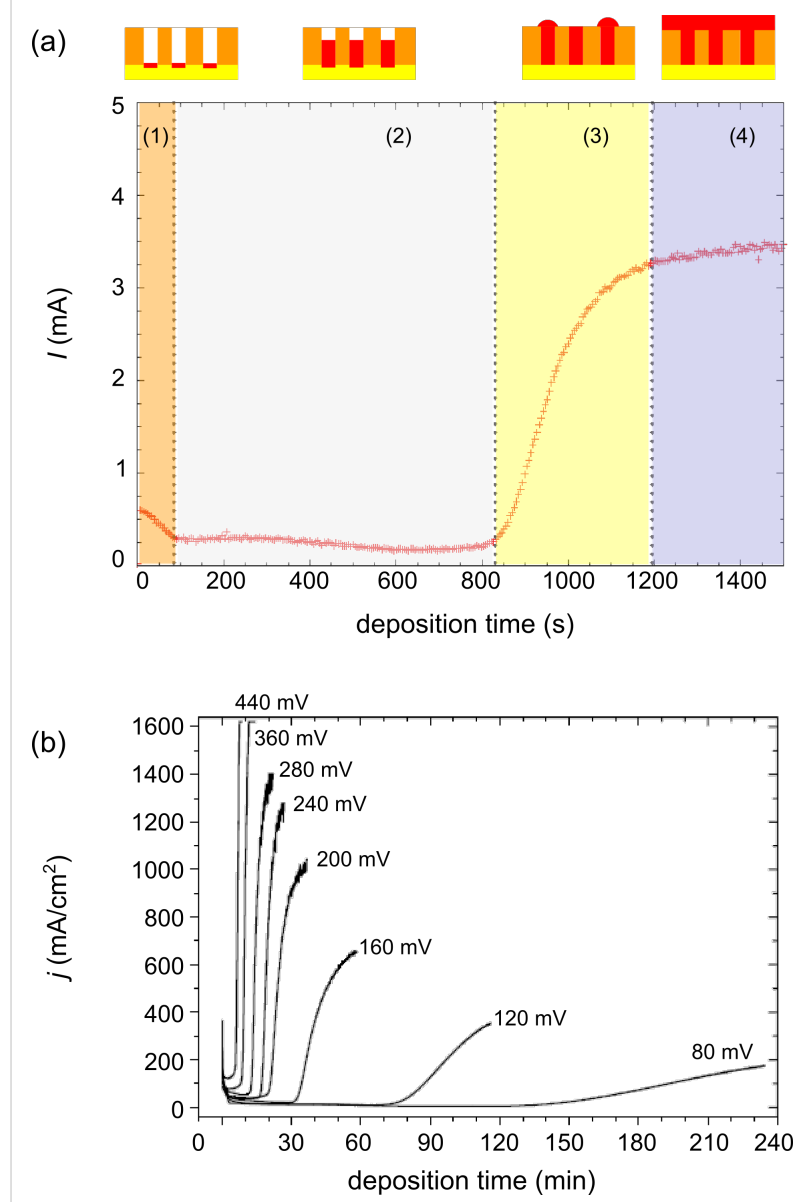

Figure 6: (a) Representative l-t curve and schematic of the four different deposition regimes. (b) Chronoamperometric curves recorded during growth of $\mathrm{Cu}$ nanowires in identical templates $(30 \mu \mathrm{m}$ thick PC, $10^{7}$ channels $/ \mathrm{cm}^{2}$, pore diameter $450 \mathrm{~nm}$ ) in a solution consisting of $0.25 \mathrm{~mol} / \mathrm{L} \mathrm{CuSO} \cdot 5 \mathrm{H}_{2} \mathrm{O}$ and $2 \mathrm{~mol} / \mathrm{L} \mathrm{H}_{2} \mathrm{SO}_{4}$, by applying different potentials (versus $\mathrm{Ag} / \mathrm{AgCl} / 3 \mathrm{~mol} / \mathrm{L} \mathrm{KCl}$ provided with a Haber-Luggin capillary). Adapted with permission from [59] - Copyright 2003 The Electrochemical Society, Inc.

\section{Composition and crystallinity of the nanowires}

During electrochemical growth of nanowires, two mechanisms occur simultaneously inside the membrane channels: (i) nucleation of new grains and (ii) growth of existing nuclei. To 
synthesize single-crystalline micro- or nanowires, the fabrication conditions should be chosen such that the second process dominates [61]. It should be noted, that other than on a macroelectrode surface, the wire deposition process occurs in a recessed electrode ensemble, and that the cathode surface is placed, at the beginning of the process, at the bottom of the channels and shifts to the opposite surface during the nanowire growth [59].

Control over the crystallinity is especially important when the size of the investigated nanostructures is comparable to characteristic length scales such as electron and phonon mean free paths and Fermi wavelength. For nanomaterials, phenomena such as electrical and thermal resistivity or magnetoresistance are known to depend strongly on their crystallinity and morphology [62-64]. Also the surface plasmon resonances show pronounced effects on size, material, and shape $[65,66]$. A detailed morphological and crystallographic characterization of the synthesized nanostructures is required (i) to understand how the synthesis parameters influence the resulting crystalline structure, and (ii) to investigate size-dependent nanowire properties relevant for different applications. The following sections present results from systematic studies of the influence of the growth parameters on the resulting crystallinity and morphology of nanowires of various materials.

\subsection{Copper nanowires}

Copper is an important material for the microelectronic industry due to its low resistivity and its low vulnerability to electromigration, a phenomenon that produces voids in wires and ultimately causes failure. Copper micro- and nanostructures in addition are synthesized for applications in solar cells, flatpanel displays, and sensorics. The most common approaches to synthesize copper micro- and nanostructures include electrodeposition, chemical vapour deposition, electroless deposition, and solution growth [67-69]. Among them, electrochemical deposition is most suitable for fabrication of nanostructures in trenches of small dimensions and/or high aspect ratios (length/ diameter) [70].

Based on the above-described template technique, poly- and single-crystalline $\mathrm{Cu}$ nanowires with aspect ratios above 500 and diameters as small as $30 \mathrm{~nm}$ were synthesized by electrodeposition in PC etched ion-track membranes. A suitable electrolyte is, e.g., an aqueous solution containing $238 \mathrm{~g} / \mathrm{L}$ $\mathrm{CuSO}_{4} \cdot 5 \mathrm{H}_{2} \mathrm{O}$ and $21 \mathrm{~g} / \mathrm{L} \mathrm{H}_{2} \mathrm{SO}_{4}$ [52]. The high concentration of $\mathrm{CuSO}_{4}$ guarantees a sufficiently large supply of ions inside the pores during the deposition. Addition of sulphuric acid increases the conductivity of the solution and lowers the cathode overvoltage. Electrodeposition is typically performed potentiostatically in a two-electrode arrangement by using a copper anode, at temperatures between 25 and $70{ }^{\circ} \mathrm{C}$. By applying low overvoltages, side reactions, such as hydrogen evolution, are avoided. Figure 7 displays transmission electron microscopy (TEM) images of representative (a) single- and (b) polycrystalline $\mathrm{Cu}$ nanowires together with their respective selected-area electron diffraction (SAED) pattern. The singlecrystalline $\mathrm{Cu}$ wire was deposited at $50{ }^{\circ} \mathrm{C}$ by applying a voltage of $U_{\mathrm{c}}=-50 \mathrm{mV}$. The wire exhibits cylindrical geometry with constant diameter and a smooth contour over the entire length. The polycrystalline wire was deposited at room temperature and at a larger negative potential. Its contour is clearly rougher, probably due to the higher growth rate. Increase of surface roughness with increasing deposition potential has also been observed in the case of Bi compound wires [58]. X-ray diffraction (XRD) performed on the single-crystalline nanowire arrays by using a four-circle diffractometer, revealed a preferred orientation of the (110) planes perpendicular to the wire axis [71].

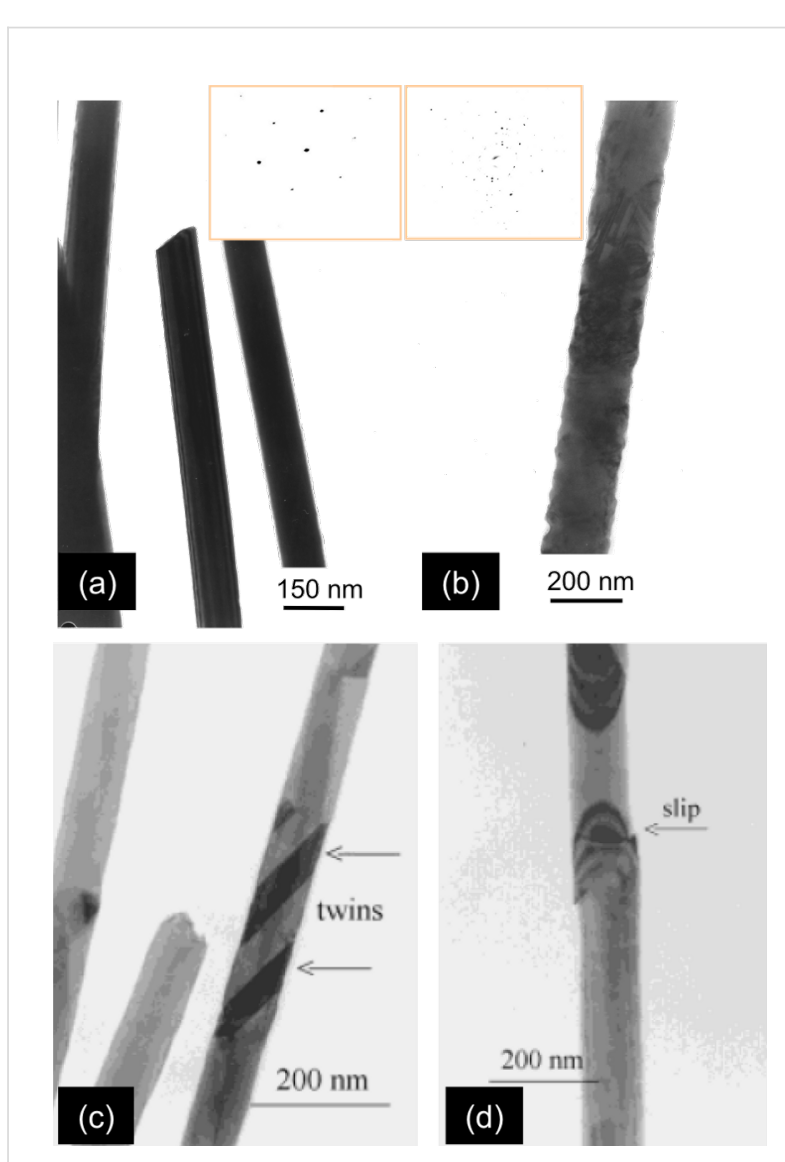

Figure 7: TEM images of representative Cu nanowires and lattice defects: (a) single-crystalline and (b) polycrystalline $\mathrm{Cu}$ wires together with their corresponding SAED patterns (insets). (c) $70 \mathrm{~nm}$ diameter single-crystalline wire with twin structures. (d) Slip in a $100 \mathrm{~nm}$ diameter Cu wire. $(a, b)$ Adapted with permission from [71] - Copyright 2001 Elsevier and (c,d) adapted with permission from [52] - Copyright 2001 Wiley-VCH. 
Recently, Duan et al. presented an exhaustive investigation of the preferred orientation of $\mathrm{Cu}$ nanowire arrays, demonstrating that their preferred crystallographic orientation can be adjusted along the [111], [100] or [110] directions by selecting specific parameters with respect to the sulphuric acid concentration in the electrolyte, the applied voltage, and the deposition temperature [72]. It was also reported that single-crystalline $\mathrm{Cu}$ microwires were grown under room-temperature conditions by using commercial baths and reverse-pulse plating in an ultrasonic bath in a two-electrode arrangement [73]. Copper nanowires were also synthesized in a three-electrode arrangement by using a SCE as reference electrode [59]. Cylindrical multilayered $\mathrm{Cu} / \mathrm{Cu}_{2} \mathrm{O}$ nanowires were electrochemically deposited from the self-oscillating $\mathrm{Cu}(\mathrm{II})$-lactate system by using PC templates [74].

Figure $7 \mathrm{c}$ shows the TEM image of a twinned region, as frequently found in single-crystalline $\mathrm{Cu}$ wires. Twinning is a crystal defect characterized by the partial displacement relative to the matrix of a considerable number of neighbouring crystallographic planes $[75,76]$ and is evident by the reduced brightness in Figure 7c. Twins can be created during the growth process but may also result from plastic deformation when handling the samples. Also slips are frequently observed, not only in $\mathrm{Cu}$ wires (Figure 7d) but also in other materials such as $\mathrm{Au}$ and $\mathrm{Bi}_{2} \mathrm{Te}_{3}$. Planar defects such as twinning or slips are expected to influence the electrical and thermal transport properties, as well as the mechanical stability of nanowires.

\subsection{Gold nanowires}

Numerous theoretical predictions and experiments have demonstrated that $\mathrm{Au}$ nanoparticles and nanowires are promising elements for sensoric, optical and biomedical applications. Of special interest are surface plasmon resonances (SPRs) of $\mathrm{Au}$ nanostructures, because electromagnetic radiation is confined to a volume of sub-wavelength dimensions. It is known that field enhancements due to SPRs are strongly dependent on size, geometry, and composition of the nanostructures $[65,66]$.

Systematic studies were performed on the electrochemical template synthesis of Au-nanowires in a two-electrode configuration by using a sputtered $\mathrm{Au}$ film as initial cathode and a $\mathrm{Au}$ rod as anode. The investigations provided adequate growth conditions for both single- and polycrystalline wires with diameters between 20 and $100 \mathrm{~nm}[53,54]$. Other than for copper, nanowires deposited by using the ammonium gold(I) sulfite electrolyte (gold content $=15 \mathrm{~g} / \mathrm{L}$, Metakem $\mathrm{GmbH}$, Usingen, Germany), or the sodium disulfitoaurate(I) Imabrite 24 bath (gold content $=12.3 \mathrm{~g} / \mathrm{L}$, Schloetter Galvanotechnik, Geislingen/Steige, Germany) exhibit a polycrystalline structure independently of temperature and voltage. In contrast, wires grown in a solution of potassium dicyanoaurate(I) (Puramet 402 bath, gold content $=10 \mathrm{~g} / \mathrm{L}$, Doduco, Pforzheim, Germany) yield single crystals at temperatures between 50 and $65^{\circ} \mathrm{C}$ under both direct-current and reverse-pulse deposition conditions. The resulting single-crystalline wires have a preferred [110] orientation.

Figure 8a shows a representative TEM image of a polycrystalline $\mathrm{Au}$ nanowire deposited with an ammonium gold(I) sulfite electrolyte, at $50{ }^{\circ} \mathrm{C}$, by applying $U_{\mathrm{c}}=-500 \mathrm{mV}$ between cathode and anode. Several zones of light and dark contrast reveal several grain boundaries along the wire axis. The TEM image in Figure 8c depicts a single-crystalline wire deposited with the cyanidic electrolyte at $U_{\mathrm{c}}=-900 \mathrm{mV}$ and $60{ }^{\circ} \mathrm{C}$, while the cell was immersed in an ultrasonic bath. The authors reported that the presence of ultrasound fields improved the convection in the pores and thus the homogeneity of the growth on the whole sample, leading to homogeneous wire arrays. The crystallinity of the different wires is confirmed by the respective SAED patterns (insets). Further, the XRD pattern of the polycrystalline wires indicates random orientation (Figure $8 b$ ), while single-crystalline wires have a preferred orientation of the (110) planes perpendicular to the wire axis (Figure 8d).

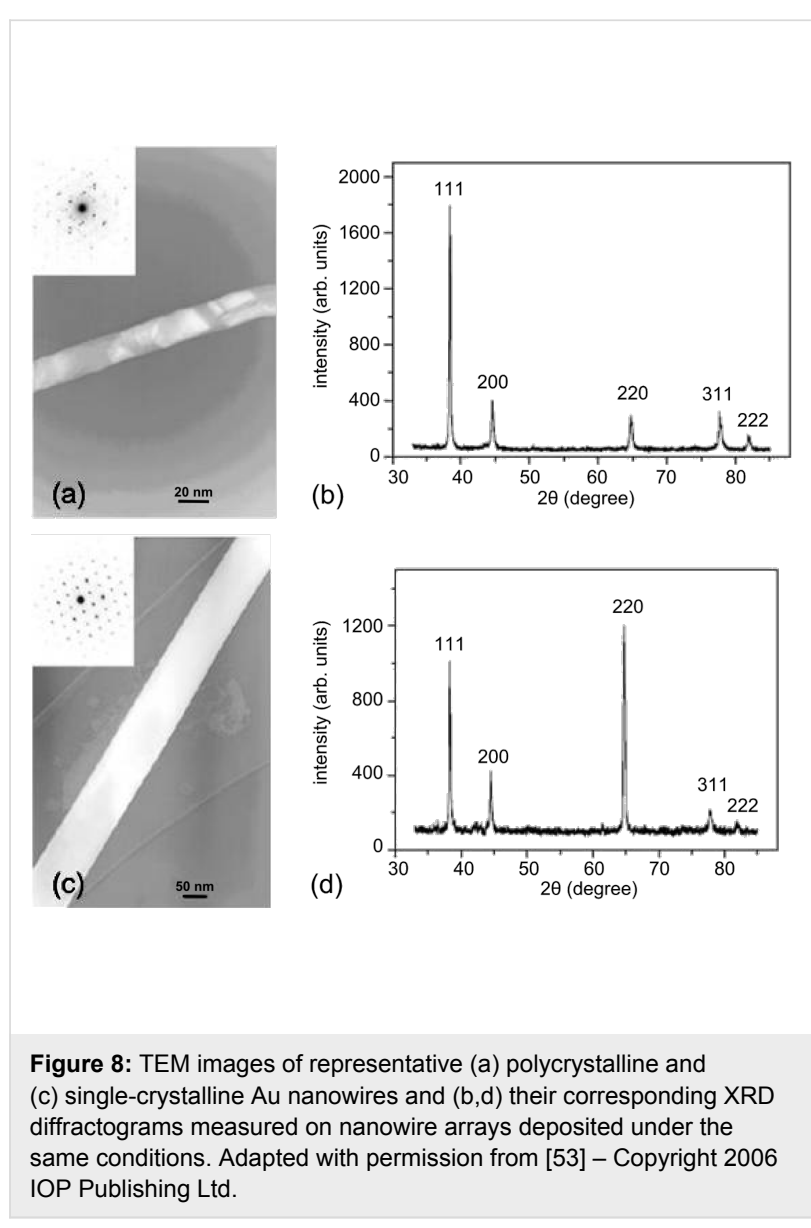




\subsection{Nanowires from other metals}

In the recent past, nanowires of a number of different metals have been synthesized, including $\mathrm{Pt}, \mathrm{Pb}, \mathrm{Ni}, \mathrm{Co}$, and $\mathrm{Fe}$. Platinum is a noble metal with interesting nanowire applications in sensorics and catalysis.

Recently, the synthesis of Pt nanowires at $65{ }^{\circ} \mathrm{C}$ from an alkaline platinum bath (Platinum-OH, Metakem) in a two electrode arrangement by using a Pt rod as anode was reported by Rauber et al. [55]. Contrary to copper and gold, the crystallinity of nanowires of metals with high melting temperatures, such as $\mathrm{Pt}$ and $\mathrm{Rh}$, is difficult to control through the deposition parameters (i.e., to control nucleation and surface diffusion processes at the cathode). TEM and XRD investigations revealed a fine-grained polycrystalline structure for all potentiostatic conditions applied. Multisegmented polycrystalline Pt nanowires with preset and controlled number of segments/interfaces were synthesized by pulse-reverse electrodeposition. The cathodic pulse was applied at a potential $U_{\mathrm{c}}=-1.3 \mathrm{~V}$ for different pulse durations ranging from $t_{\mathrm{c}}=1 \mathrm{~s}$ to $t_{\mathrm{c}}=20 \mathrm{~s}$. The anodic pulse was invariably timed to $t_{\mathrm{a}}=1 \mathrm{~s}$ at $U_{\mathrm{a}}=0.4 \mathrm{~V}$. In this process, the length of the segments is controlled by the duration of the cathodic pulse [55].

As demonstrated by Yi and Schwarzacher, single- and polycrystalline $\mathrm{Pb}$ nanowires of $50 \mathrm{~nm}$ diameter grow reproducibly in etched ion-track membranes for various pulse parameters. An interesting finding is that the superconducting transition temperature $T_{\mathrm{c}}$ depends on the crystallinity of the nanowires [78].

Magnetic nanowires were successfully grown from nickel [57], cobalt [79], and iron [80]. The growth of Fe-based nanowires with controllable size, aspect ratio, and magnetic anisotropy in $\mathrm{FeCl}_{3}$ and $\mathrm{FeCl}_{2}$ solutions was investigated by Song et al. They employed $\mathrm{FeCl}_{3}$ and $\mathrm{FeCl}_{2}$ solutions, studied the nanowire growth mechanism and provided real-time compositional and crystallographic information [80].

\subsection{Bismuth and bismuth-compound nanowires}

Due to its unique electronic properties, bismuth is a very interesting material to study the effect of finite- and quantumsize effects of nanostructures $[9,81,82]$. Characteristic length scales, such as the electron mean free path and Fermi wavelength are relatively large at room temperature, namely 100 and $40 \mathrm{~nm}$, respectively $[83,84]$. Bulk $\mathrm{Bi}$ is a semimetal with a very small indirect band overlap, and its charge carrier density is low compared to conventional metals. Moreover, the electron effective mass is small (0.001-0.26) and depends on the crystalline orientation. Given these characteristics, size effects on Bi structures are expected at relatively large dimen- sions $(\approx 100 \mathrm{~nm})$. Also compound nanostructures of $\mathrm{Bi}_{1-x} \mathrm{Sb}_{x}$ and $\mathrm{Bi}_{2} \mathrm{Te}_{3}$ are being intensively investigated due to theoretical studies predicting a large enhancement of the thermoelectric efficiency, given by the so-called figure of merit $Z T, Z T=$ $S^{2} \cdot \sigma \cdot T / \kappa$, where $S$ is the Seebeck coefficient, $\sigma$ is the electrical conductivity, $\kappa$ is the thermal conductivity and $T$ is the temperature. The power factor $\left(S^{2} \sigma\right)$ of these thermoelectric nanomaterials should increase due to quantum size effects and the thermal conductivity should decrease due to enhanced phonon surface scattering [85-88]. The thermoelectric properties of these Bi-compound materials are anisotropic and are extremely sensitive not only to composition and size, but also to the crystallographic orientation of the wires. During synthesis, it is thus important to control these three parameters simultaneously. To achieve a significant enlargement of the thermoelectric efficiency, the diameter of such nanowires should be below $30 \mathrm{~nm}$.

Cornelius et al. fabricated pure Bi nanowires using an electrolyte consisting of $0.2 \mathrm{M} \mathrm{BiCl}_{3}, 0.3 \mathrm{M}$ tartaric acid, $0.2 \mathrm{M} \mathrm{NaCl}$, $1.3 \mathrm{M} \mathrm{HCl}$, and $100 \mathrm{~g} / \mathrm{L}$ glycerol, in most cases potentiostatically, but also using reverse-pulse deposition in a two-electrode arrangement [56]. The thin Au layer acted as cathode and a Bi rod as anode. XRD and TEM revealed that the nanowires deposited potentiostatically are $<110>$ textured. At higher temperatures and smaller overpotentials, the texture increases. At $T=60{ }^{\circ} \mathrm{C}$ and low overpotentials (e.g., $U_{\mathrm{c}}=-17 \mathrm{mV}$ ), single-crystalline wires are produced (Figure 9a). In contrast, wires deposited with reverse pulses exhibit a $<100>$ texture and are polycrystalline with grain sizes of ca. $0.5 \mu \mathrm{m}$ (Figure $9 \mathrm{~b}$ ). Bi nanowires with other preferred orientations have been synthesized by other techniques, such as low-temperature solvothermal process and high-pressure injection in alumina $[89,90]$.

Recently, $\mathrm{Bi}_{2} \mathrm{Te}_{3}$ nanowires with diameters from $150 \mathrm{~nm}$ down to $10 \mathrm{~nm}$, and lengths of up to $60 \mu \mathrm{m}$, were potentiostatically grown by using a thermostated three-electrode setup with a thin sputtered Au layer acting as the cathode, a Pt counter electrode, and a SCE as the reference electrode [58]. The electrolyte consisted of an aqueous solution of bismuth nitrate pentahydrate, $\mathrm{TeO}_{2}$, and nitric acid. As shown by means of XRD, TEM, SEM, and EDX (energy-dispersive X-ray analysis), the parameters involved in the electrodeposition process, $T, U$, and diameter, density, and length of the channels in the template, influence the morphology, crystallinity, and preferred crystallographic orientation of the wires in a complex manner. The $\mathrm{Bi}_{2} \mathrm{Te}_{3}$ nanowires have diameters and lengths interesting for both basic research on thermoelectric nanomaterials and development of thermoelectric devices. Figures 9c-e display SEM images of $\mathrm{Bi}_{2} \mathrm{Te}_{3}$ nanowires with average diameters (c) 14, (d) 19 and (e) $24 \mathrm{~nm}$. The smallest Bi-compound wires synthesized so far had diameters as small as $9-10 \mathrm{~nm}$ (inset). To the 


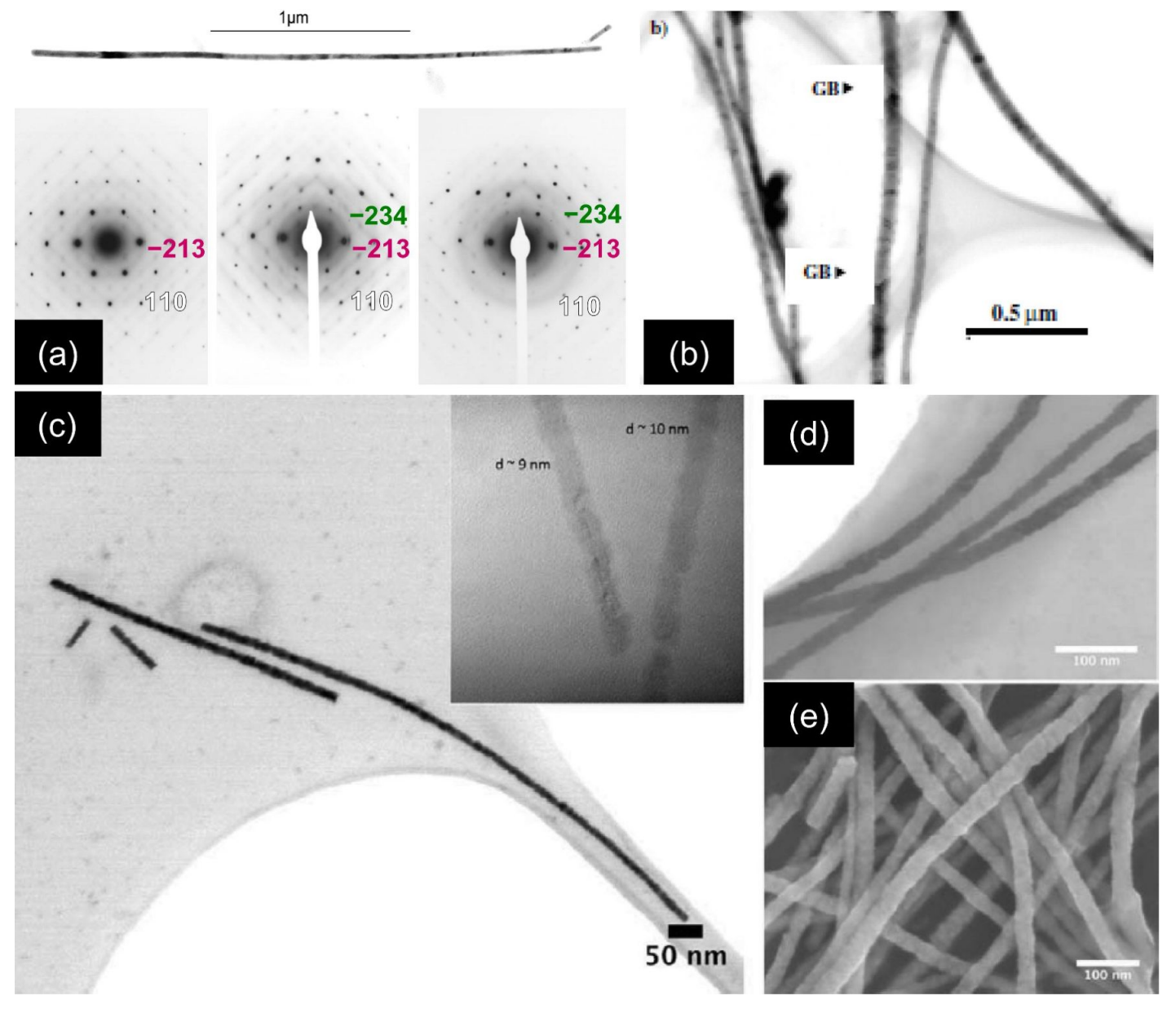

Figure 9: TEM images of $\mathrm{Bi}$ and $\mathrm{Bi}_{2} \mathrm{Te}_{3}$ nanowires: (a) individual single-crystalline $\mathrm{Bi}$ nanowire deposited under potentiostatic conditions together with SAED patterns from different wire positions and (b) several polycrystalline wires grown under pulsed conditions. Series of SEM images displaying $\mathrm{Bi}_{2} \mathrm{Te}_{3}$ nanowires with average diameters of (c) 14 , (d) 19 and (e) $24 \mathrm{~nm}$. The inset displays TEM images of sections with diameter 9-10 nm. $(a, b)$ Adapted with permission from [56] - Copyright 2005 IOP Publishing Ltd and (c-e) adapted with permission from [58] - Copyright 2012 American Chemical Society.

best of our knowledge, with $14 \mathrm{~nm}$ average diameter, $10 \mu \mathrm{m}$ length, and aspect ratios between 700 and 1000, these are presently the thinnest nanowires produced by electrodeposition in polymer membranes.

Polycrystalline $\mathrm{Bi}_{1-x} \mathrm{Sb}_{x}$ nanowires were successfully electrodeposited from an aqueous solution of $\mathrm{BiCl}_{3}$ and $\mathrm{SbCl}_{3}$, with simultaneous control over the diameter (between 20 and $200 \mathrm{~nm})$, and varying $\mathrm{Sb}$ concentration $(0.05 \leq \mathrm{x} \leq 0.4)$. Coarseand fine-tuning of the $\mathrm{Sb}$ concentration was achieved by selecting proper electrolyte composition and potential [60]. Figure 10 displays HRTEM images of $20-30 \mathrm{~nm}$ diameter nanowires deposited at $U=-200 \mathrm{mV}$ versus SCE and for different $\mathrm{Sb}$ concentrations in the electrolyte $(c(\mathrm{Sb})=0.01$ (a), 0.02 (b), 0.03 (c), and $0.04 \mathrm{~mol} / \mathrm{L}$ (d)), together with their respective EDX spectra (e). On average, the concentration of $\mathrm{Sb}$ in the wires was found to be $x=0.07,0.18,0.26$, and 0.41 , respectively. With increasing $\mathrm{Sb}$ concentration, the $d$-spacings belonging to the $\{012\}$ lattice planes decrease, as evident by white lines in the HRTEM images (Figures 10a-d). XRD investigations on the preferred crystallographic orientation of $\mathrm{Bi}_{2} \mathrm{Te}_{3}$ and $\mathrm{Bi}_{1-x} \mathrm{Sb}_{x}$ nanowires grown in templates are described in references $[58,60]$.

All experimental results reported so far clearly demonstrate that electrodeposition of thermoelectric nanowires in etched iontrack membranes enable the control of various wire parameters. It is particularly important to control the alloy composition and to obtain wire diameters as small as possible, because large enhancements in TE performance are expected when quantum size effects and enhanced phonon scattering come into play. 

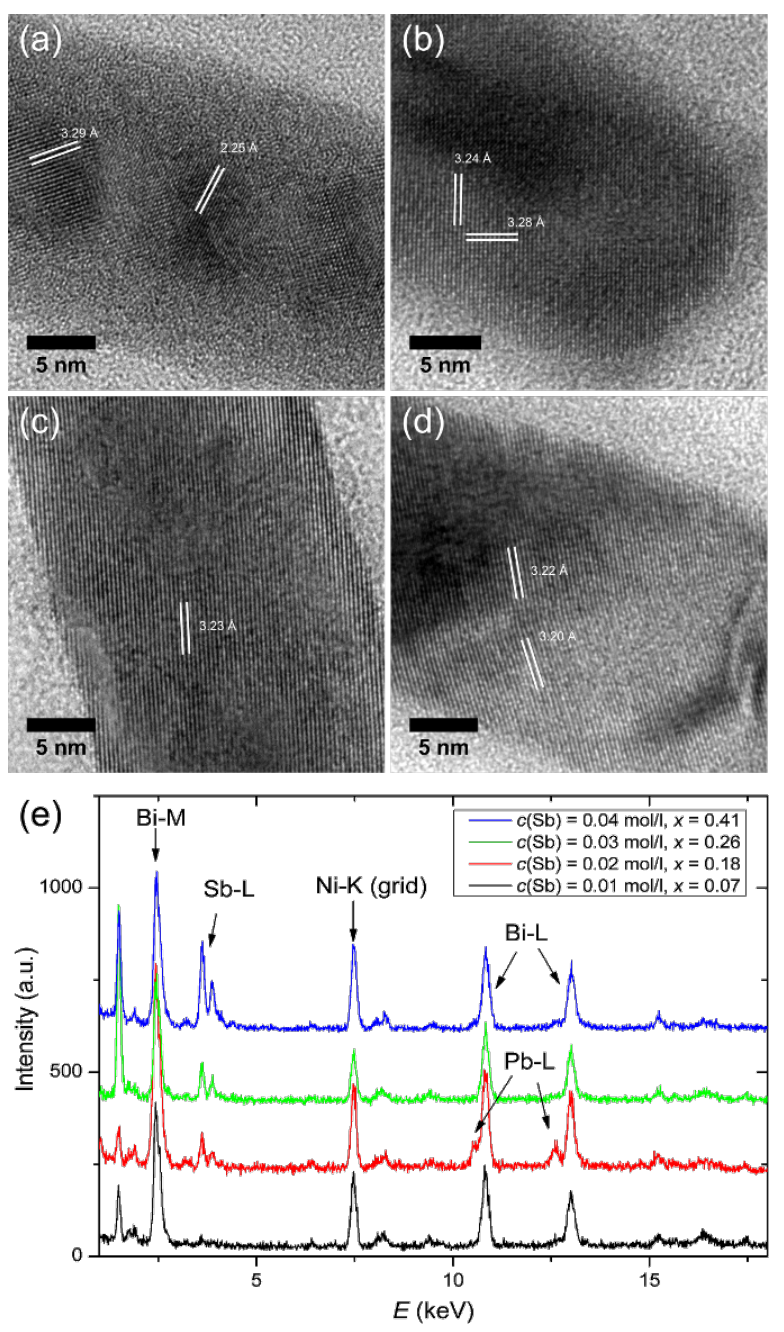

Figure 10: TEM images of $\mathrm{Bi}_{1-x} \mathrm{Sb}_{x}$ nanowires deposited at $U=$ $-200 \mathrm{mV}$ versus SCE from electrolytes with Sb concentrations $(c(\mathrm{Sb}))$ of (a) 0.01, (b) 0.02, (c) 0.03 and (d) $0.04 \mathrm{~mol} / \mathrm{L}$. (e) Corresponding EDX spectra, indicating the following Sb concentration in the wires $x$ : $0.07,0.18,0.26$ and 0.41 . Adapted with permission from [60] - Copyright 2011 American Chemical Society.

\subsection{Semiconductor nanowires}

Semiconductor nanowires are excellent candidates to be functional elements in applications as diverse as optics, sensorics, and electronics, and energy applications such as thermoelectrics and hydrogen generation by water splitting [2-4,91]. In the past two decades, enormous progress has been achieved in the synthesizing and characterizing of semiconductor nanowires of controlled size and composition. Synthesis techniques include mostly vapour-liquid-solid growth, solution-phase, lithography, and electroless etching [2,10], while the template method in combination with electrodeposition of semiconductor nanowires (such as $\mathrm{ZnO}, \mathrm{Si}$, or $\mathrm{ZnTe}$ ) has been rather limited.
Cylindrical $\mathrm{ZnO}$ nanowires have been electrochemically grown from aqueous solutions in the pores of both alumina and etched ion-track membranes with a rather limited range of diameters. Lai et al. reported the synthesis of $\mathrm{ZnO}$ nanowires using a $\mathrm{ZnSO}_{4}$-based electrolyte at $22{ }^{\circ} \mathrm{C}$, and a $\mathrm{Zn}\left(\mathrm{NO}_{3}\right)_{2}$-based solution at $70^{\circ} \mathrm{C}$ [92]. Enculescu and co-authors reported the fabrication and optical characterization of $\mathrm{ZnO}$ wires with diameters between $80 \mathrm{~nm}$ and $1.5 \mu \mathrm{m}$, deposited in etched ion track membranes using a $\mathrm{Zn}\left(\mathrm{NO}_{3}\right)_{2}$-based electrolyte at $70{ }^{\circ} \mathrm{C}$, with a $\mathrm{Pt}$ foil and a SCE electrode as counter and reference electrodes, respectively [93]. By appropriately tuning the composition of the electrolyte, they also synthesised doped $\mathrm{ZnO}$ nanowires. By using, for instance, an electrolyte containing $\mathrm{Zn}\left(\mathrm{NO}_{3}\right)$, $\mathrm{Co}\left(\mathrm{NO}_{3}\right)$, nitric acid, and polyvinylpyrrolidone (PVP) as an additive, $300 \mathrm{~nm}$ diameter $\mathrm{Zn}_{1-x} \mathrm{Co}_{x} \mathrm{O}$ nanowires with $x$ ranging from 0.01 to 0.05 were grown [94].

The synthesis and properties of semiconducting CdTe and CdS nanowires are being investigated for their potential in photodetector and photovoltaic applications. CdTe and CdS rods are mostly synthesized by chemical vapour deposition, and sol-gel processes. Electrodeposition of stoichiometric CdTe nanowires with diameters between $80 \mathrm{~nm}$ and $1 \mu \mathrm{m}$ was reported by Enculescu et al. [95]. In addition to SEM, TEM, EDX, and XRD characterization, they also determined the band gap of nanowire arrays by reflection spectroscopy measurements [96]. Kum et al. reported the synthesis of $\approx 50 \mathrm{~nm}$ diameter CdTe wires and studied the influence of electrolyte, temperature, potential, and $\mathrm{pH}$ value on the composition and crystallinity of the nanowires [97]. They also demonstrated that as-deposited CdTe nanowires consist of nanocrystals with grain sizes up to $60 \mathrm{~nm}$. Thermal annealing increases the wire resistivity and influences the grain size. The preparation of CdTe nanowire diodes with semiconductor homojunctions by using a single electrodeposition bath consisting of cadmium sulfate $(0.02 \mathrm{M})$ and tellurium dioxide $(1 \mathrm{mM})$ as sources of cadmium and tellurium ions, respectively, was described by Matei et al. [98]. The tellurium dioxide was dissolved in $50 \%$ concentrated sulfuric acid and the overall $\mathrm{pH}$ was adjusted to 2 with sodium hydroxide. Polyvinylpyrrolidone $(1 \mathrm{~g} / \mathrm{L})$ was added as a wetting agent. A Pt foil and a SCE acted as counter and reference electrode, respectively. The potentiostatic electrodeposition of $\mathrm{CdS}$ nanowires by using an electrolyte solution containing $\mathrm{CdCl}_{2}$ and thioacetamide, at $70{ }^{\circ} \mathrm{C}$ was reported by Mo et al. [99].

Finally, due to its availability, inertness, and compatibility with silicon-based technical processing, Si nanowires have a broad range of applications from sensorics, to biotechnology, photonics, IR-sensorics, and many others. Si wires have been prepared by a large variety of deposition techniques, including chemical vapour deposition, laser ablation, or thermal evapor- 
ation. The first template-grown nanowires of amorphous $\mathrm{Si}$ were recently reported by using ionic liquids $[100,101]$. Ionic liquids have proved to be a good alternative electrolyte to fabricate materials such as $\mathrm{Al}, \mathrm{Ti}, \mathrm{Si}$, or $\mathrm{Ge}$, which cannot be electrodeposited in aqueous solvents [102]. Given the extreme versatility of etched ion-track membranes, future electrochemical growth of Si nanowires would allow tuning size parameters and provide interesting freestanding high-aspect ratio Si nanoor microstructures [103].

\subsection{Segmented nanowires}

Besides synthesizing single metal and semiconductor nanowires, electrodeposition also offers the possibility to grow segmented multimaterial nanowires. Combining various materials of interest can provide specific functionalities that are not present in the individual segments. Variations in composition along the length of the wire can, e.g., be used to incorporate electrical functionality, optical contrast, and/or desired surface chemistry [104]. Segmented Au/Pt nanowires were demonstrated to move autonomously when placed in a hydrogen peroxide solution [105]. Also, biofunctionalized nanowire bar codes were used for ss-DNA detection [106]. In addition, it is also of interest to grow metal segments on both sides of a semiconductor nanowire in order to provide electrical contacts.

To synthesize two-component multisegment nanowires, a single electrolyte bath containing the two ions of interest is employed. At less negative potentials, only the more noble metal is deposited, while at more negative potential, both metals are deposited. By keeping the concentration of the more noble metal in the electrolyte much lower than the concentration of the less noble metal, the less noble metal is mainly deposited containing a small fraction of the nobler one [64]. Alternatively, a two-bath sequential deposition can be employed. Multilayer nanowires were electrodeposited in etched ion-track membranes in the nineties to study the perpendicular-to-plane giant magnetoresistance (GMR) [64]. Multilayered nanowires reported so far include the following material combinations: $\mathrm{Co} / \mathrm{Cu}, \mathrm{NiFe} / \mathrm{Cu}$, $\mathrm{CoNi} / \mathrm{Cu}, \mathrm{Ni} / \mathrm{Cu}, \mathrm{Ni} / \mathrm{Au}, \mathrm{AgPt}, \mathrm{Co} / \mathrm{Pt}$, and $\mathrm{Fe} / \mathrm{Cu}$ [107-109]. In addition metal-semiconductor-metal junctions, such as $\mathrm{Ni}-\mathrm{ZnO}-\mathrm{Ni}$ and $\mathrm{CdTe}-\mathrm{Ni}$, were electrodeposited [110].

\subsection{Cap morphology as an indication of wire crys- tallinity}

When the grown nanowires reach the top side of the porous membrane, the deposition continues outside the pores forming so-called caps (Figure 6a, zone 3). The shape and morphology of the caps are a direct indication of the crystalline structure of the wires as shown for various materials (e.g., $\mathrm{Cu}, \mathrm{Au}, \mathrm{Bi}, \mathrm{Sb}$ ). Round caps are typically formed on top of polycrystalline wires (Figure 11a), while facetted caps grow on top of single-crystal- line wires, or on wires consisting of large grains (Figure 11b-d). The facetted Au caps (Figure 11b) exhibit a cubic shape, revealing the cubic structure of the corresponding Au wires. In the case of $\mathrm{Cu}$ (Figure 11c), the caps often exhibit a five-fold symmetry. Such morphology is ascribed to multiple twinned crystals consisting of five deformed tetrahedral subunits. The morphology of the facetted Bi caps (Figure 11d) also reveals twinning.
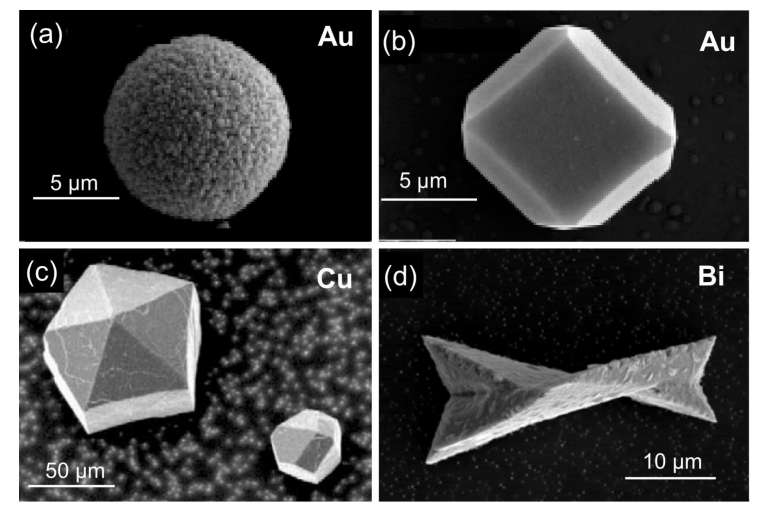

Bi

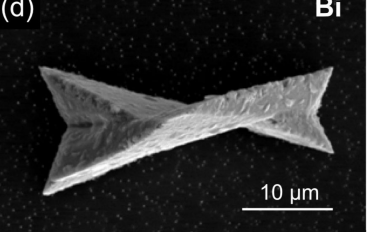

Figure 11: SEM images revealing the characteristic morphology of various metallic caps: (a) polycrystalline $\mathrm{Au}$, (b) single-crystalline $\mathrm{Au}$, (c) twinned $\mathrm{Cu}$ and (d) twinned $\mathrm{Bi}$. (a,b) Adapted with permission from [54] - Copyright Springer Verlag 2006; (c) adapted with permission from [71] - Copyright 2005 Elsevier Science Ltd.; (d) adapted with permission from [56] - Copyright 2005 IOP Publishing Ltd.

\section{Nanowire morphology}

The morphology of nanowires, including their geometry, size, and surface contour, is primarily determined by the shape of the hosting channels. The production of templates with swift heavyion beams in combination with track etching enables us to control several template parameters such as well-defined channel shape and channel geometry, with the diameter adjustable between a few nanometres up to micrometres, membrane thickness up to $100 \mu \mathrm{m}$, and aspect ratios up to 1000 . In addition, by varying the fabrication steps in a controlled manner, novel structures can be synthesized, such as pores with conical geometry or channels with smooth or rough inner walls. By exposing the samples to the ion beam under various tilting angles, nanochannel networks with controlled density and interconnection degree are possible. Figure 12 displays a selection of wire morphologies and wire arrangements recently obtained by ion-track technology at GSI: (a,b) rough nanowires; (c) conical nanowires [111]; and (d) nanowire networks.

\subsection{Surface roughness}

Smooth cylindrical nanowires are suitable for many applications, including sensing of electrical or optical signals. However, in some cases an increased surface roughness is of interest. Hochbaum et al. and Boukai et al. recently reported 


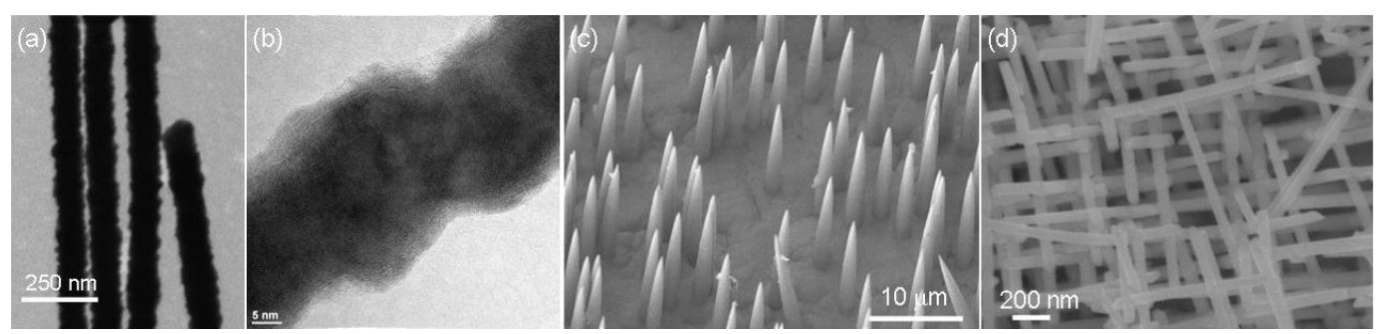

Figure 12: (a) SEM and (b) TEM images displaying the rough contour of Sb nanowires electrodeposited in PET membranes. (c) Array of freestanding conical Cu nanowires. (d) Network of interconnected Sb nanowires. Adapted with permission from [60] - Copyright 2011 American Chemical Society.

that rough $\mathrm{Si}$ nanowires exhibit a thermal conductivity up to 100 times smaller than their smooth counterparts, becoming promising objects to be implemented in thermoelectric devices $[87,88]$. In addition, a larger roughness effectively increases the available surface, and thus can be an important advantage, e.g., for catalytic and photovoltaic applications. We have been able to tune the surface roughness of the electrodeposited nanowires by selecting suitable polymer membranes: etched tracks in PC result in smooth channel walls, while channels in PET have a rough surface. Figures $12 \mathrm{a}$ and $12 \mathrm{~b}$ display two exemplary nanowires with diameter 90 and $30 \mathrm{~nm}$, respectively, deposited in PET channels. The variations in diameter along the wire axis amount to $30 \%$ in the case of $30 \mathrm{~nm}$ diameter wires [60].

\subsection{Conical shape}

Arrays of nanostructures of cylindrical and conical geometry are promising electrodes for field emission, photovoltaic applications, water splitting, or surface-enhanced Raman spectroscopy $[112,113]$. The individual cones potentially combine the advantages offered by the reduced dimensions of the tip with the enhanced mechanical stability provided by the large base [114]. An array of freestanding conical $\mathrm{Cu}$ wires with a large base of $1-3 \mu \mathrm{m}$ and a small tip of a few tens of nanometres is shown in Figure 12c. As mentioned above, the apex angle of the cones is determined by the geometry of the hosting conical channel (cf. section 2). Different electrodeposition conditions were studied in order to obtain mechanically stable nanocones with good electrical contact to the substrate. Electrodeposition by using a $\mathrm{CuSO}_{4}$-based electrolyte in a two electrode configuration, with $U=-40 \mathrm{mV}$ leads to a slow growth rate, resulting in a large uniform array of mechanically stable $\mathrm{Cu}$ cones of about $28 \mu \mathrm{m}$ length, $1.2 \mu \mathrm{m}$ base radius, and $190 \mathrm{~nm}$ tip radius [115]. The field-emission properties of similar $\mathrm{Cu}$-nanocone cathodes were investigated by using a field emission scanning microscope (FESM) under ultrahigh vacuum conditions [116]. The improved mechanical stability and solid contact interface of the copper nanocones resulted in much higher emission current values as compared to all previously tested metallic cylindrical nanowires [115,117].

\subsection{Nanowire networks}

Implementation of nanowire cathodes in fields such as energy harvesting, sensing, or catalysis requires a successful assembly of the nanostructures into 2-D and 3-D architectures [118,119]. Fabrication of 3-D nanowire superstructures by vapour-liquid-solid processes has been reported; however, revealing a limited tunability of the relevant parameters. Recently, Rauber et al. demonstrated the fabrication of highly ordered Pt nanowire networks, consisting of well-defined interconnected nanowires with controlled morphology [120]. Ion irradiation of polymer foils at several incident angles in consecutive steps, followed by chemical etching results in novel etched ion-track membranes with nanochannel arrays tilted at various angles. Electrodeposition in the nanochannel network results in highly ordered 3-D nanowire ensembles. An example of a complex $\mathrm{Sb}$ nanowire network is presented in Figure 12d.

\subsection{Nanogap structures}

Novel nanowire dimer and nanogap structures are interesting for applications in plasmonic sensing as well as nanoelectronics $[121,122]$. However, the reliable fabrication of such structures remains a challenge. Techniques such as break-junction techniques and gap narrowing by electroplating have been employed, but their precision and reproducibility is limited $[123,124]$. The template technique offers a promising approach by sequential deposition of multi-material-segmented nanowires grown in porous templates followed by selective etching of one of the deposited elements. This variation of the template method is also known as "on-wire lithography" [125]. Recent experiments yielded segmented $\mathrm{Au}$-rich/Ag-rich/Au-rich nanowires, synthesized by sequential potentiostatic deposition using an electrolyte containing both $\left[\mathrm{Ag}(\mathrm{CN})_{2}\right]^{-}$and $\left[\mathrm{Au}(\mathrm{CN})_{2}\right]^{-}$ions [126]. The duration of the sequential pulses controls the length of the silver-rich and gold-rich segments. After dissolution of the polymer membrane, the wires are dispersed in isopropanol. The solution containing the segmented wires is drop-cast onto a substrate. In a subsequent step, the substrate is dipped into concentrated nitric acid to dissolve the silver segments of the wires selectively. The generation of gaps with sizes between 
(a)

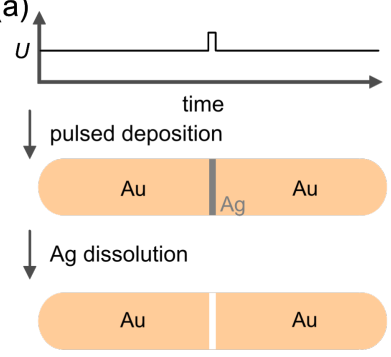

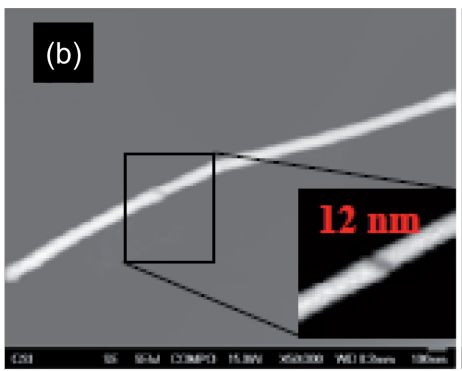

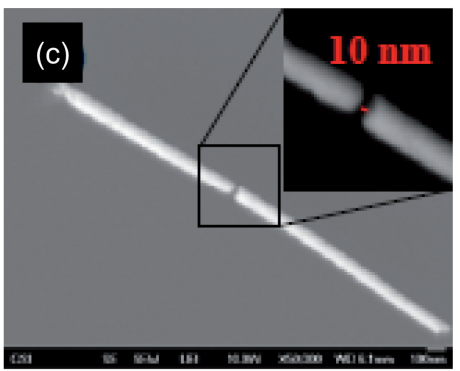

Figure 13: (a) Schema of the electrodeposition and gap-forming process. SEM images of (b) Au-rich/Ag-rich/Au-rich nanowire, and (c) Au nanowire dimer exhibiting a $10 \mathrm{~nm}$ gap after selective Ag dissolution. The corresponding insets show details of the Ag segment and the gap, respectively.

7 and $30 \mathrm{~nm}$ is demonstrated [127]. Figure 13 displays schematically the fabrication process (Figure 13a) and shows SEM images of $\mathrm{Au}$ nanowire dimers before (Figure 13b) and after (Figure 13c) silver dissolution.

\section{Size-dependent properties}

Nanowires synthesized by electrodeposition in etched ion-track membranes of a large variety of metal, semiconductor and semimetals, whose morphological and crystallographic characteristics can be adjusted in a controlled way as presented above, constitute ideal objects for the investigation of both finite- and quantum-size effects. Due to its technological relevance, size effects on the optical, electrical, and thermal properties are of special interest. The following section presents recent results by the GSI group on electrical, optical, and thermal size effects of electrodeposited nanowires.

\subsection{Finite-size effects in electrical properties}

Systematic investigations of the electrical transport properties of metal and semiconductor nanowires are necessary in order to better understand classical size effects such as electron scattering at surfaces and grain boundaries. These effects lead to an increase of the specific resistivity of the wire under study compared to its bulk counterpart, which is relevant to nanowire applications such as field-effect transistor sensors, and interconnectors. The influence of grain boundary scattering on the resistivity was predicted decades ago by Mayadas and Shatzkes, and depends on parameters such as electron mean free path, average grain size, and a reflection coefficient at the grain boundaries [128]. The effect of surface scattering was predicted by Dingle et al., and is influenced by nanowire diameter and the specularity of scattering processes at the wire surface [129].

Absolute measurements of the specific resistivity of nanowires require contacting individual nanowires in a reliable manner. The production of low-resistance contacts between nanostructures and macroscopic electronics is a difficult and challenging task. In the case of nanowires, several techniques have been already reported using, for example, the metal-coated tip of a scanning force microscope, optical and electron beam lithography, or manipulators [130-132]. In the case of electrodeposited nanowires, most groups reported the production of large arrays of wires and the subsequent selection of individual wires being contacted with lithographic techniques. Electrical resistivity of individual lithographically contacted $\mathrm{Cu}$ nanowires monitored over many hours revealed the critical problem of oxidation. During the measurement, the wire resistance increased from a few hundred ohms to several megaohms. Due to oxidation, the nanowire characteristics change from the metallic to the semiconducting regime [130].

Another possibility for contacting single nanowires is based on single-ion irradiation of polymer foils [51]. The single-wire fabrication and contacting process is schematically presented in Figure 14. The steps include (a) the fabrication of a single-pore membrane by ion irradiation and etching; (b) deposition of a suitable substrate; (c) electrochemical growth of a single nanowire (e.g., $\mathrm{Cu}, \mathrm{Au}, \mathrm{Bi}$ ) and continuation of the deposition process until a micrometre-sized cap grows on top of the wire; and (d) contacting of the embedded nanostructure by sputtering (a)

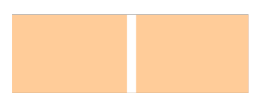

(b)

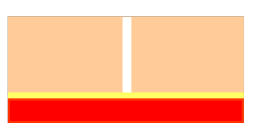

(c)

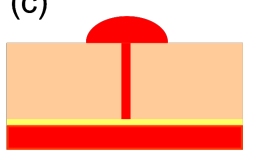

(d)

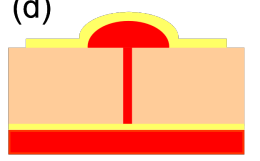

(e)

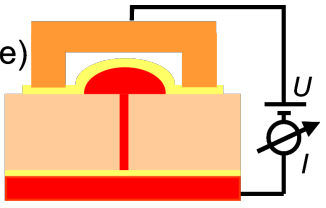

Figure 14: (a-e) Schematic of the fabrication and contacting process for a single nanowire. 
a conductive layer on the membrane surface. The process avoids the delicate handling of the nanowires and thus minimizes the risk of mechanical damage. Systematic resistivity measurements were performed with single $\mathrm{Bi}$ and $\mathrm{Au}$ nanowires of various diameters ranging between $40 \mathrm{~nm}$ and $1 \mu \mathrm{m}$ [133-135].

Figure 15 and Figure 16 display the specific electrical resistivity of individual nanowires as a function of the nanowire diameter for $\mathrm{Bi}$ and $\mathrm{Au}$, respectively. In the case of $\mathrm{Bi}$, the electrochemical growth was performed by using three different sets of deposition voltage and temperature. Each of these three wire groups had, thus, a common mean grain size. Figure 15 displays the electrical resistivity of individual $\mathrm{Bi}$ nanowires with diameters ranging between $150 \mathrm{~nm}$ and $1 \mu \mathrm{m}$, which were fabricated by electrochemical deposition in single-pore PC membranes [133].

By using three different sets of deposition voltage and temperature, three groups of single Bi wires could be deposited, each group being characterized by a common mean grain size. The results demonstrate that the resistivity of nanowires with diameters well above $100 \mathrm{~nm}$ can be up to eight times higher than for the bulk. For a given diameter, the wire resistivity becomes larger with diminishing grain size due to electron scattering at grain boundaries, providing evidence that the resistivity of nanostructures can be tailored by a suitable choice of the crystalline properties. In the case of Au, all wires show a higher specific resistivity than bulk gold (Figure 16). For diameters larger than $100 \mathrm{~nm}$, the resistivity is nearly constant, with an average value 1.8 times larger than the bulk value,

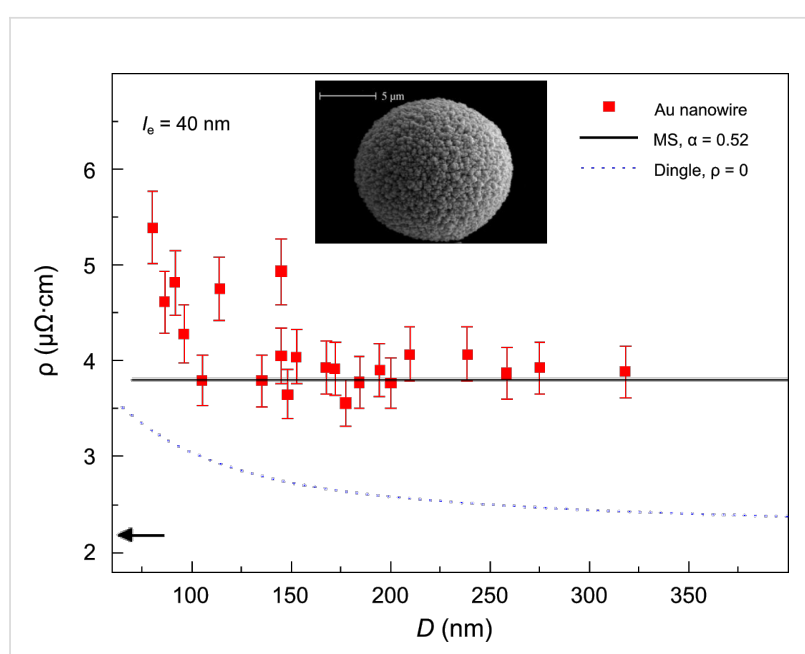

Figure 16: Specific electrical resistivity versus wire diameter for single polycrystalline gold nanowires (ammonium gold(I) sulfite electrolyte, $T=50^{\circ} \mathrm{C}, U=-0.8 \mathrm{~V}$ ) together with the cap morphology. The symbols represent the data. The continuous and dashed lines are a fit of the resistivity predicted by the Mayadas and Shatzkes and the Dingle models, respectively. Adapted with permission from [135] - Copyright 2008 Elsevier B.V.

attributed as well to grain-boundary scattering. For $d<100 \mathrm{~nm}$ the resistivity increases with decreasing diameter, due to additional scattering at the wire surface [135].

Resistance-versus-temperature curves revealed linear characteristics down to $70 \mathrm{~K}$ in the case of $\mathrm{Au}$ and a nonmonotonic behaviour in the case of $\mathrm{Bi}[133,135]$. The special configuration of a single nanowire embedded and contacted in single

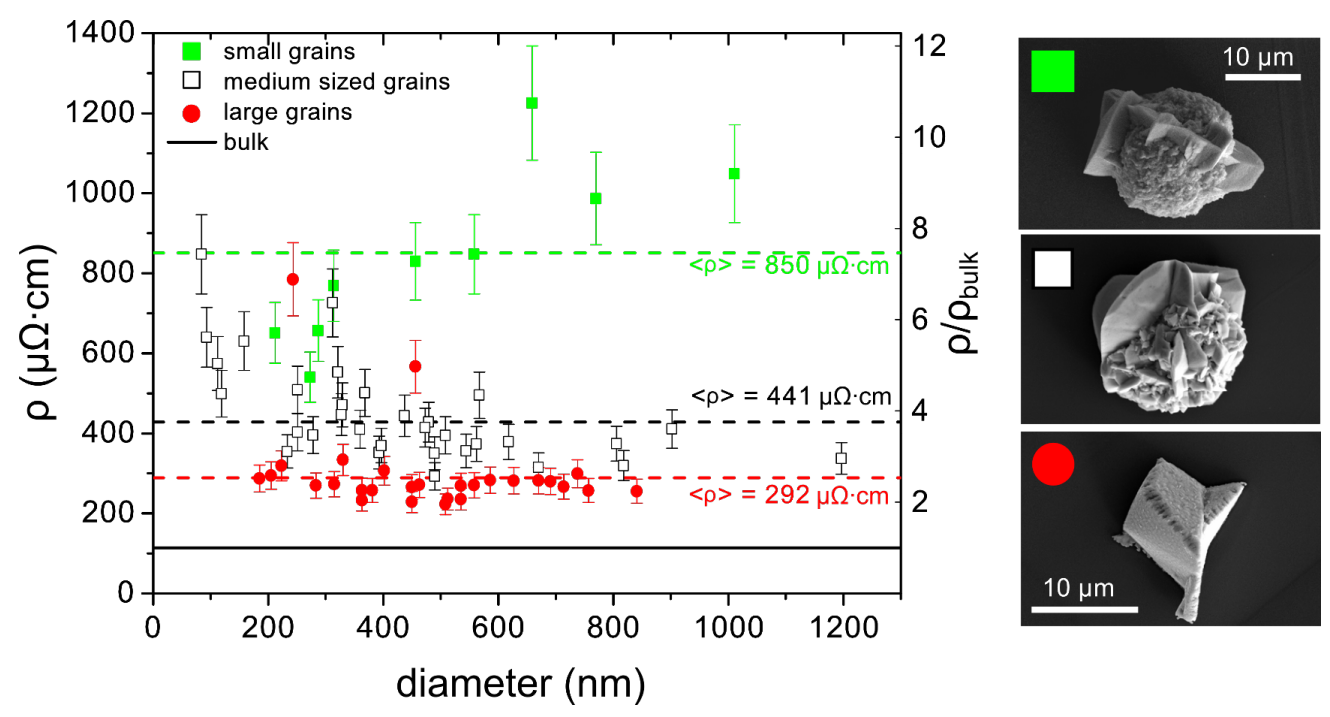

Figure 15: Specific electrical resistivity as a function of diameter of single bismuth nanowires fabricated under three different deposition conditions ( $T$ and $U$ ): $30^{\circ} \mathrm{C}$ and $-50 \mathrm{mV}$ (green squares); $50^{\circ} \mathrm{C}$ and $-25 \mathrm{mV}$ (open black squares); $60^{\circ} \mathrm{C}$ and $-17 \mathrm{mV}$ (red circles). The solid line represents the classical behaviour, while the dotted lines are the average resistivity values for the indicated deposition conditions. SEM images illustrate the corresponding cap morphology. Adapted with permission from [133] - Copyright 2006 American Institute of Physics. 
nanopore membranes also allows the determination of the maximum current density before failure. Embedded Bi nanowires were found to withstand three to four orders of magnitude higher current densities than bulk Bi. The fact that thinner Bi nanowires can carry higher current densities is attributed to more efficient heat dissipation to the surrounding polymer matrix [136]. For Bi nanowires with a diameter comparable to the Fermi wavelength (i.e., $d \approx 100 \mathrm{~nm}$ ) theoretical calculations predicted that the charge-carrier confinement leads to splitting of the energy bands into sub-bands, and a shift of conduction and valence bands with respect to each other. Such a quantum-size effect was experimentally observed by infrared spectroscopy, revealing a shift of the absorption edge to higher energies with decreasing wire diameter [137].

\subsection{Surface plasmon resonances in Au nano- antennas}

Collective charge-density oscillations due to surface plasmons exhibited by metal nanoparticles, and in particular by $\mathrm{Au}$ nanowires and nanowire dimers (two nanowires separated by a small gap), are being investigated with great interest due to the strongly enhanced electromagnetic fields formed at the nanowire tips and at the gap $[123,138]$. These surface plasmon resonances (SPRs) are characteristic of each particle and depend on material, dielectric constant of the surrounding medium, and geometry $[65,66]$. By controlling the length of the nanowire, antenna nanostructures exhibiting SPR at a given frequency of interest can be synthesized. Suitable $\mathrm{Au}$ and $\mathrm{Cu}$ nanoantennas with specific micrometre length and about $100 \mathrm{~nm}$ diameter were fabricated by electrodeposition in PC etched ion-track templates. After dissolution of the polymer membrane, the nanowires were transferred onto infrared (IR)-transparent substrates. Single nanowires were studied at the synchrotron light source ANKA (Forschungszentrum Karlsruhe), with respect to their antenna-like plasmon resonances [138]. The results showed that the resonances depend not only on length and diameter of the wire but also on the substrate and surroundings. Neubrech et al. demonstrated that the IR vibration signals of one attomol of molecules can be detected with enormous sensitivity when the broadband resonance of the nanoantenna matches the IR active vibration dipoles of the molecules [139]. The application of such single nanoantennas and dimers in fields such as surface-enhanced IR absorption or surfaceenhanced Raman scattering requires not only an excellent control over the nanostructure synthesis, but also a fundamental understanding of the near-field characteristics of the antennas.

Near-field investigations were provided by scanning transmission electron microscopy combined with high-resolution electron-energy-loss spectroscopy (STEM-EELS) using a Zeiss SESAM TEM operated at $200 \mathrm{kV}$ with a field-emission gun and equipped with a MANDOLINE energy filter. This technique allows us to study the transversely and longitudinally localized surface plasmon resonances in single nanowires and nanowire dimers excited by the rapidly travelling electron beam depending on the beam position. Figure 17 a shows the highresolution plasmonic field-intensity map obtained by acquisition from top to bottom (red arrow) of 50 electron-energy-loss spectra at equidistant positions along the long axis of a gold-silver alloy nanowire ( $L=907 \pm 5 \mathrm{~nm}, D=107 \pm 5 \mathrm{~nm})$. The map reveals different plasmon modes, which we assign to the first five longitudinal LSP modes and a transversal mode, and which are schematically presented at the top of Figure 17a. Figure $17 \mathrm{~b}$ shows a single spectrum of the mapping in Figure $17 \mathrm{a}$, recorded at one side-end of the wire (red dot in TEM picture). Figure 17c displays the plasmonic mapping of a dimer of two nanowires separated by an $\approx 8 \mathrm{~nm}$ gap $\left(L_{1}=\right.$ $784 \pm 5 \mathrm{~nm}, D_{1}=112 \pm 5 \mathrm{~nm}, L_{2}=808 \pm 5 \mathrm{~nm}, D_{2}=$ $112 \pm 5 \mathrm{~nm}$ ). In the case of nanowire dimers, the splitting of the longitudinal multipole modes into bonding and antibonding modes up to the third order (Figure 17c,d) was investigated. Interestingly, the transversal resonance is not excited when positioning the electron beam at the gap and decays rapidly with increasing distance from the wire surface. Figure $17 \mathrm{~d}$ displays spectra recorded at the dimer ends (blue and green), and at the dimer gap (red). The positions are marked in the TEM image, with dots of the corresponding colours.

\subsection{Thermal instability}

A successful implementation of nanowire-based devices requires a knowledge of and ability to control the behaviour of the nanostructures at elevated operation temperatures. The thermal stability of nanomaterials is controlled by surface and diffusion processes and influenced by the material characteristics, temperature, and geometrical parameters [140-144]. In particular, it was predicted that nanowires may fragment into a chain of nanospheres above a temperature that is much lower than the corresponding bulk melting temperature $T_{\mathrm{m}}$. Based on previous theoretical studies by Plateau and Lord Rayleigh on the instability of liquid cylinders and liquid jets [145,146], Mullins and Nichols performed calculations on the thermal instability of solid cylinders considering mass transport by surface and volume diffusion [147]. For a cylinder with initial radius $r$ and a sinusoidal perturbation $R=r+\Delta r_{0} \sin (2 \pi x / \lambda)$, perturbations with wavelength $\lambda>2 \pi r$ are expected to increase spontaneously in amplitude and become more pronounced with time. The solid cylinder will finally break up into a row of spheres with an average spacing $\lambda_{\mathrm{m}}$ and diameter $d$. Both, $\lambda_{\mathrm{m}}$ and $d$ should depend on various factors such as the type of diffusion dominating the transformation, the crystallographic characteristics of the structure, or the surroundings (e.g., the substrate). 



Figure 17: (a) TEM image of the single Au nanowire (length $907 \mathrm{~nm}$, width $107 \mathrm{~nm}$ ) and the corresponding high-resolution plasmonic field intensity map. The map consists of 50 electron-energy-loss spectra measured along the long axis of the nanowire (cf. direction of arrow next to wire, average distance of scan line to nanowire $\approx 15 \mathrm{~nm}$ ). The energy interval, plotted from left to right, ranges from 0.2 to $3.0 \mathrm{eV}$. The colour indicates the number of counts (white highest). The dotted lines indicate the different multipole modes. (b) Electron energy-loss spectrum measured at one end of the single nanowire (the red dot in the TEM image marks the position of measurement). (c) Plasmonic field intensity map consisting of 60 electron energy-loss spectra measured along a nanowire dimer (red arrow) separated by an $\approx 8 \mathrm{~nm}$ gap. The scan lines have an average distance to the wire of $\approx 10 \mathrm{~nm}$. The schematics at the top represent the electric-field distribution along the dimer. (d) Electron-energy-loss spectra measured at the two ends of the dimer (blue and green lines) and a spectrum measured in the dimer gap (red line). The coloured dots in the TEM image inset specify the measurement positions for each spectrum. Adapted with permission from [126] - Copyright 2011 American Chemical Society.

Systematic thermal annealing experiments studying the morphological transformation of electrodeposited $\mathrm{Cu}$ and $\mathrm{Au}$ nanowires confirmed that the Rayleigh instability concept is also applicable to metal nanowires [148,149]. In the case of $\mathrm{Cu}$, the fragmentation of nanowires with diameters below $50 \mathrm{~nm}$ occurs at temperatures between 400 and $600^{\circ} \mathrm{C}$. HRSEM beautifully visualizes the different stages of the fragmentation process at different temperatures and for different wire diameters (Figure 18a-d).

After annealing at $400{ }^{\circ} \mathrm{C}$, the wire displays diameter fluctuations along the wire axis (Figure 18a) developing into points of fragmentation (Figure 18b). At this temperature the length of the segments is several hundred nanometres. After annealing at 

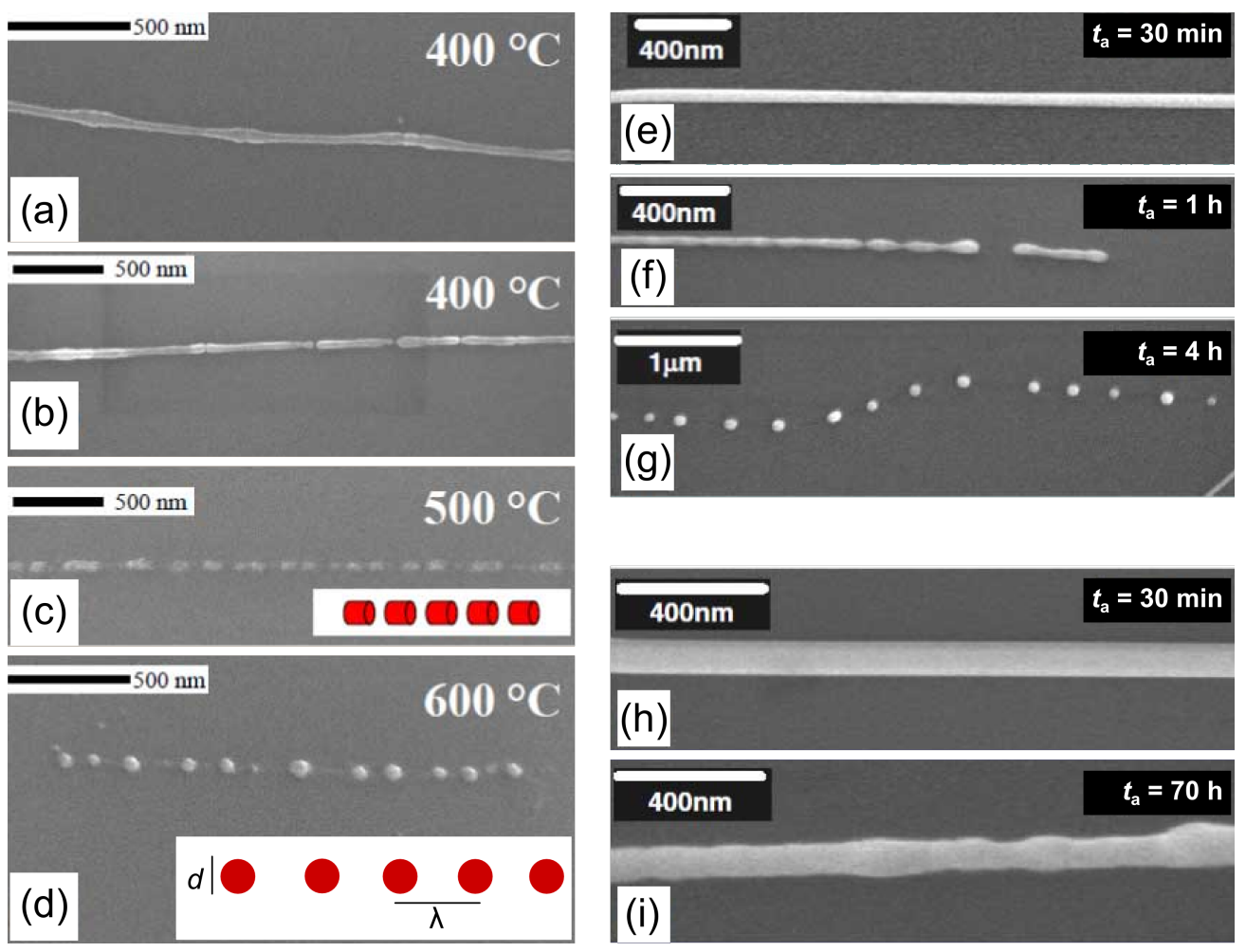

Figure 18: HRSEM micrographs of $\mathrm{Cu}$ nanowires of diameter $30 \mathrm{~nm}$ after $30 \mathrm{~min}$ annealing at different temperatures (a-d), and Au nanowires of two different diameters annealed for various times at $500^{\circ} \mathrm{C}$. The insets represent schematically the fragment geometry, including sphere size and spacing, as modelled by Nichols and Mullins. (e-g) $50 \mathrm{~nm}$ diameter Au nanowires after annealing for $30 \mathrm{~min}(\mathrm{e}), 1 \mathrm{~h}(\mathrm{f})$, and $4 \mathrm{~h} \mathrm{(g)} \mathrm{at} 500{ }^{\circ} \mathrm{C}$. (h-i) 100-nm diameter Au nanowires after $30 \mathrm{~min}(\mathrm{~h})$ and $70 \mathrm{~h}$ (i) annealing. Due to the larger diameter, the wires are more stable and display only soft oscillations after extended annealing. (a-d) Adapted with permission from [148] - Copyright 2004 American Chemical Society; (e-i) adapted with permission from [149] - Copyright 2006 IOP Publishing Ltd.

$500{ }^{\circ} \mathrm{C}$, the wires decay into shorter sections of length about $100 \mathrm{~nm}$ (Figure $18 \mathrm{c}$ ). Finally at $600^{\circ} \mathrm{C}$, copper nanowires decay into a linear row of spheres (Figure 18d). In the case of $\mathrm{Au}$, nanowires with a diameter of $25 \mathrm{~nm}$ develop radial fluctuations already at $300{ }^{\circ} \mathrm{C}$ and decay completely into chains of spheres at $500{ }^{\circ} \mathrm{C}$ [149]. Figure $18 \mathrm{e}-\mathrm{g}$ show evidence for the influence of annealing time on the morphological evolution of $\approx 50 \mathrm{~nm}$ diameter nanowires during annealing at $500{ }^{\circ} \mathrm{C}$. For a given temperature, wider nanowires require significantly larger annealing times to induce Rayleigh instability (Figure 18h-i).

The thermal stability is also influenced by the nanowire structure. Single-crystalline Au nanowires oriented along the $<110>$ direction were found to be more stable and required longer annealing times to complete their geometrical transformation into spheres than their polycrystalline counterparts [150]. For both metals, $\mathrm{Au}$ and $\mathrm{Cu}$, the final formation of a chain of nanospheres occurs at a temperature much below the melting point $\left(T_{\mathrm{m}}(\mathrm{Cu})=1083{ }^{\circ} \mathrm{C}, T_{\mathrm{m}}(\mathrm{Au})=1064{ }^{\circ} \mathrm{C}\right)$. Recently Zhou et al. reported the fragmentation of $\mathrm{Ni}$ nanowires by the Rayleigh criterion at temperatures of about $900{ }^{\circ} \mathrm{C}\left(T_{\mathrm{m}}(\mathrm{Ni})=1453{ }^{\circ} \mathrm{C}\right)$ [151]. This seems to indicate a direct relationship between the bulk melting temperature of the constituent materials and the maximal temperature at which thermal stability is exhibited. These results reveal that prior to nanoscale device applications, technological problems arising from the thermal instability of nanostructures must be seriously taken into account. The positive aspect of the Rayleigh instability is its potential application for converting nanowires into long chains of nanospheres, and the possibility of controlling surface diffusion processes at the nanoscale by applying elevated temperatures.

An interesting nanoscale diffusion phenomenon was recently observed for micrometre-long electrodeposited $\mathrm{Cu}$ nanowires, confined in a graphitic coating. In situ TEM observation showed that at $500{ }^{\circ} \mathrm{C}$ nanowires experience a geometrical transformation into single-crystalline nanoparticles of up to 10 -fold increased diameter [152]. Real-time movies recorded in situ visualized the $\mathrm{Cu}$ draining out of the carbon coating (Figure 19).

Figure 19a shows a TEM image of two encapsulated $\mathrm{Cu}$ nanowires $(d \approx 30 \mathrm{~nm})$ intersecting each other on a TEM grid. The wires are covered by a thin carbon layer. The snapshots of 

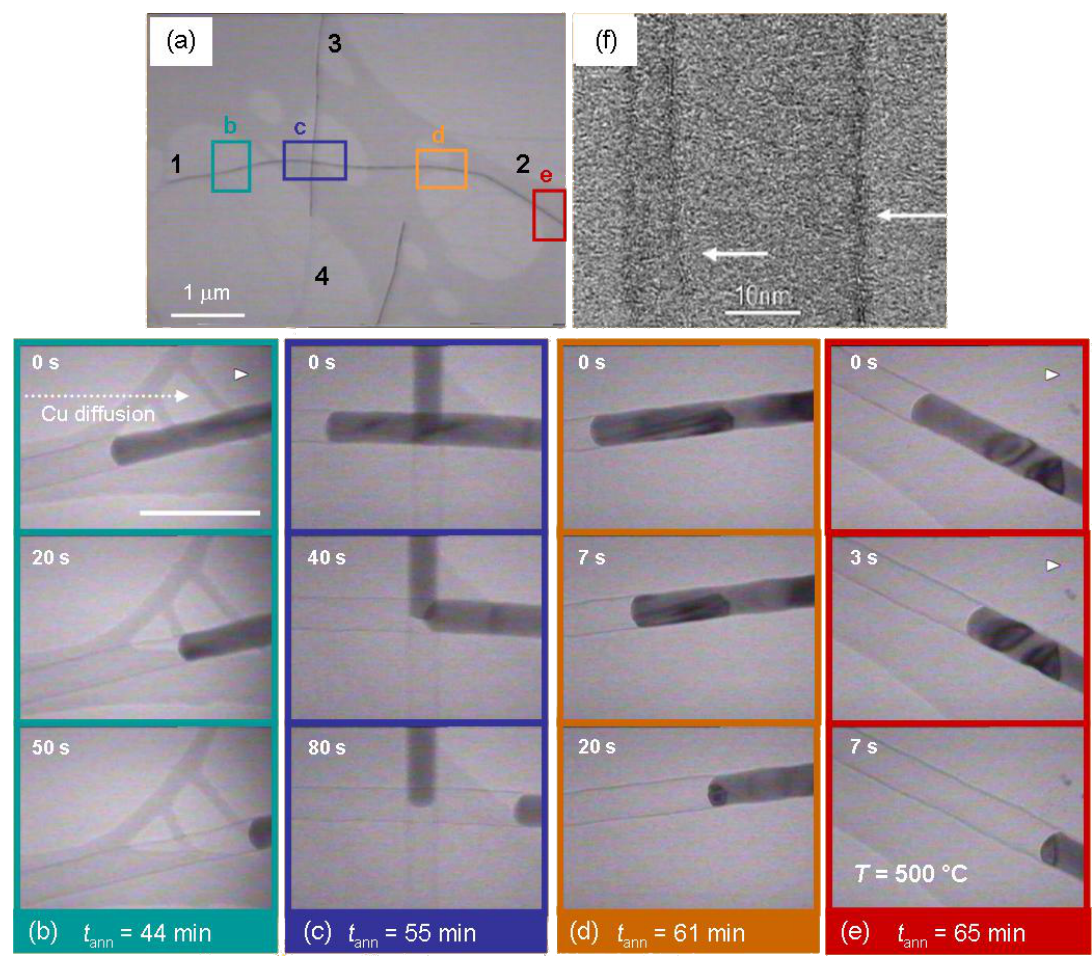

Figure 19: TEM images and video snapshots of Cu nanowire (covered by carbon coating) recorded on four areas marked in (a) at different annealing times: (b) 44, (c) 55, (d) 61, and (e) 65 min. In each case, the time series (from top to bottom) show how the Cu filling moves from left to right, while the carbon shell (f) remains unchanged. The $100 \mathrm{~nm}$ scale bar in (a) applies for all snapshots. Adapted with permission from [152] - Copyright 2012 Wiley.

the video recorded on the four areas marked in Figure 19a display the effective evacuation of the solid $\mathrm{Cu}$ content out of the carbon tube over micrometre distances towards the open end (labelled as 2). The consecutive images of the video (from top to bottom, Figure 19b-e) were recorded at different annealing times $\left(t_{\mathrm{ann}}=44,55,61\right.$, and $\left.65 \mathrm{~min}\right)$. Although the temperature is constant $\left(500^{\circ} \mathrm{C}\right)$, the velocity of the $\mathrm{Cu}$ front increases with time and location during the annealing process. Details of this drainage process close to the open end of a carbon tube are shown in Figure 20a-c. Figure 20a-c shows TEM images of the $\mathrm{Cu}$ nanowire in Figure 19a, close to the end 2, taken at different times during the annealing process. This series of images visualizes the formation and growth of a nanoparticle during the annealing process. Once the process has been completed, each nanowire is transformed into a single monocrystalline, facetted $\mathrm{Cu}$ particle (Figure 20d-f).

Based on kinetic Monte Carlo simulations (Figure 20g-i) it is proposed that this dramatic morphological transformation is driven by surface diffusion of $\mathrm{Cu}$ atoms along the wire-tube interface, thus minimizing the total free energy of the system. The high-resolution micrograph displayed in Figure $19 \mathrm{f}$ displays the multishell graphitic coating presumably formed from polymer residues on the nanowire surface. It is note-
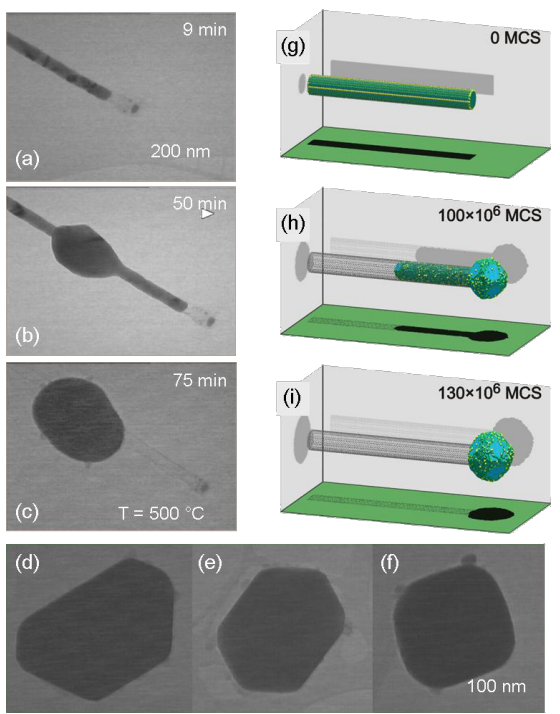

Figure 20: $(a-c)$ TEM images of a Cu nanowire close to the end of a carbon tube (field 2 in Figure 19) visualizing the formation and growth of a nanoparticle during the annealing process. (d-f) Facetted Cu crystals observed at different wire ends after $80 \mathrm{~min}$ annealing.

(g-h) Snapshots from kinetic Monte Carlo simulations showing the reaction pathway of the draining process. Time is indicated in the number of Monte-Carlo steps (MCS). Adapted with permission from [152] - Copyright 2012 Wiley. 
worthy that this carbon layer is resistant throughout the whole process. The formation and characteristics of such fascinating carbon-coated core-shell structures should be investigated in more detail. The results also show that nanowires coated by electron-beam-induced carbon tubes can serve as well-defined nanopipettes. The extraction process is initiated and controlled by temperature. The template-based electrochemical wire synthesis allows control over the wire diameter as well as length and thus provides material for nanocrystals whose size is predefined by the pipette volume.

\section{Conclusion}

We have described the synthesis of micro- and nanowires using ion-track technology in combination with electrodeposition. We illustrate how this technique enables the independent and simultaneous control of size (diameter and length), morphology, crystalline structure, and composition of the nanowires. A combination of irradiation of polymer foils with high-energy heavy ions and chemical etching results in templates with micro- and nanochannels (length of several tens of micrometres and diameter from ca. $10 \mathrm{~nm}$ to several micrometres). By electrodeposition in the channels, nanowires of different materials, such as $\mathrm{Au}, \mathrm{Cu}, \mathrm{Pt}, \mathrm{Bi}, \mathrm{Bi}_{2} \mathrm{Te}_{3}, \mathrm{ZnO}$, and $\mathrm{CdTe}$, are synthesized. The crystallographic characteristics (surface roughness, grain size, and texture) are also well controlled by various electrodeposition parameters, namely voltage, temperature, and electrolyte. Finally, several examples of recent results by the GSI group on electrical, optical and thermal size effects of electrodeposited nanowires have been presented, demonstrating that these electrodeposited nanowires constitute ideal objects for the investigation of both finite- and quantum-size effects.

\section{Acknowledgements}

The author thankfully acknowledges financial support from the Helmholtz Association, the Deutsche Forschungsgemeinschaft (DFG) within the SPP 1165 (Nanodrähte und Nanoröhren: von kontrollierter Synthese zur Funktion), and the SPP 1386 (Nanostrukturierte Thermoelektrika: Theorie, Modellsysteme und kontrollierte Synthese). M.E.T.M. thanks all co-workers and collaborators, in particular I. Alber, M. Cassinelli, N. Chtanko, T. W. Cornelius, D. Dobrev, I. Enculescu, S. Karim, J. Krieg, S. Müller, R. Neumann, O. Picht, M. Rauber, C. Schötz, I. U. Schuchert, R. Spohr, C. Trautmann, J. Vetter, and M. F. Wagner for their contributions to the investigations of the synthesis and characterization of micro- and nanowires. Strong support by the members of the Materials Research Group of GSI during beam times for the template irradiation is thankfully acknowledged. M.E.T.M thanks C. Trautmann and R. Neumann for fruitful discussions and their continuous support during our research work, as well as for correcting this manuscript.

\section{References}

1. Lieber, C. M.; Wang, Z. L. Mater. Res. Bull. 2007, 32, 99-108. doi:10.1557/mrs2007.41

2. Hochbaum, A. I.; Yang, P. Chem. Rev. 2010, 110, 527-546. doi:10.1021/cr900075v

3. Gargas, D. J.; Toimil-Molares, M. E.; Yang, P. J. Am. Chem. Soc. 2009, 131, 2125-2127. doi:10.1021/ja8092339

4. Seletskiy, D.; Hasselbeck, M. P.; Cederberg, J. G.; Katzenmeyer, A.; Toimil-Molares, M. E.; Leonard, F.; Talin, A. A.; Sheik-Bahae, M. Phys. Rev. B 2011, 84, 115421. doi:10.1103/PhysRevB.84.115421

5. Chan, C. K.; Peng, H.; Liu, G.; Mcllwrath, K.; Zhang, X. F.; Huggings, R. A.; Cui, Y. Nat. Nanotechnol. 2008, 3, 31-35. doi:10.1038/nnano.2007.411

6. Sun, J.; Liu, C.; Yang, P. J. Am. Chem. Soc. 2011, 133, 19306-19309. doi:10.1021/ja2083398

7. Holmberg, V. C.; Panthani, M. G.; Korgel, B. A. Science 2009, 326, 405-407. doi:10.1126/science.1178179

8. Krenn, J. R.; Schider, G.; Rechberger, W.; Lamprecht, B.; Leitner, A.; Aussenegg, F. R.; Weeber, J. C. Appl. Phys. Lett. 2000, 77, 3379-3381. doi:10.1063/1.1327615

9. Cornelius, T. W.; Toimil-Molares, M. E. Finite- and Quantum-size Effects of Bismuth Nanowires. In Nanowires; Prete, P., Ed.; Intech: Rijeka, Croatia, 2010; pp 274-296.

10. Xia, Y.; Yang, P.; Sun, Y.; Wu, Y.; Mayers, B.; Gates, B.; Yin, Y.; Kim, F.; Yan, H. Adv. Mater. 2003, 15, 353-389. doi:10.1002/adma.200390087

11. Cao, G. Nanostructures and Nanomaterials: Synthesis, Properties, and Applications; Imperial College Press: London, 2004.

12. Hulteen, J. C.; Martin, C. R. J. Mater. Chem. 1997, 7, 1075-1087. doi:10.1039/a700027h

13. Martin, C. R. Science 1994, 266, 1961-1966. doi:10.1126/science.266.5193.1961

14. Furneaux, R. C.; Rigby, W. R.; Davidson, A. P. Nature 1989, 337, 147-149. doi:10.1038/337147a0

15. Thurn-Albrecht, T.; Schotter, J.; Kästle, G. A.; Emley, N.; Shibauchi, T.; Krusin-Elbaum, L.; Guarini, K.; Black, C. T.; Tuominen, M. T.; Russell, T. P. Science 2000, 290, 2126-2129. doi:10.1126/science.290.5499.2126

16. Possin, G. E. Rev. Sci. Instrum. 1970, 41, 772 doi:10.1063/1.1684640

17. Williams, W. D.; Giordano, N. Rev. Sci. Instrum. 1984, 55, 410-412. doi:10.1063/1.1137752

18. Vetter, J.; Spohr, R. Nucl. Instrum. Methods Phys. Res., Sect. B 1993, 79, 691-694.

19. Chakarvarti, S. K.; Vetter, J. Radiat. Meas. 1998, 29, 149-159. doi:10.1016/S1350-4487(98)00009-2

20. Dobrev, D.; Vetter, J.; Neumann, R. Nucl. Instrum. Methods Phys. Res., Sect. B 1998, 146, 513-517. doi:10.1016/S0168-583X(98)00437-6

21. Dobrev, D.; Vetter, J.; Angert, N.; Neumann, R. Electrochim. Acta 2000, 45, 3117-3125. doi:10.1016/S0013-4686(00)00478-3

22. Dobrev, D.; Baur, D.; Neumann, R. Appl. Phys. A 2005, 80, 451-456. doi:10.1007/s00339-004-3078-z

23. Dobrev, D.; Vetter, J.; Angert, N.; Neumann, R. Appl. Phys. A 2001, 72, 729-733. doi:10.1007/s003390100872

24. Schönenberger, C.; van der Zande, B. M. I.; Fokkink, L. G. J.; Henny, M.; Schmid, C.; Krueger, M.; Bachtold, A.; Huber, R.; Birk, H.; Staufer, U. J. Phys. Chem. B 1997, 101, 5497-5505. doi:10.1021/jp963938g 
25. Datta, M. IBM J. Res. Dev. 1998, 42, 563-566. doi:10.1147/rd.425.0563

26. Trautmann, C.; Brüchle, W.; Spohr, R.; Vetter, J.; Angert, N. Nucl. Instrum. Methods Phys. Res., Sect. B 1996, 111, 70-74. doi:10.1016/0168-583X(95)01264-8

27. Bath, W.; Dahl, L.; Groening, L.; Glatz, J.; Richter, S.; Yaramyshev, S. Development of the UNILAC towards a megawatt beam injector. In Proceedings of the XXII Linac Conference, Lübeck, 2004, Schaa, V. R. W., Ed.; DESY: Hamburg, 2004; pp 246-248.

28. Dehaye, F.; Balanzat, E.; Ferain, E.; Legras, R. Nucl. Instrum. Methods Phys. Res., Sect. B 2003, 209, 103-112. doi:10.1016/S0168-583X(02)02048-7

29. Spohr, R. Method for producing nuclear traces or microholes originating from nuclear traces of an individual ion. US000004369370A, Jan 1, 1983.

30. Spohr, R. Ion Tracks and Microtechnology: Principles and Applications; Vieweg und Teubner: Wiesbaden, Germany, 1990.

31. Siwy, Z.; Apel, P.; Baur, D.; Dobrev, D. D.; Korchev, Y. E.; Neumann, R.; Spohr, R.; Trautmann, C.; Voss, K.-O. Surf. Sci. 2003, 532-533, 1061-1066. doi:10.1016/S0039-6028(03)00448-5

32. Heins, E. A.; Siwy, Z. S.; Baker, L. A.; Martin, C. R. Nano Lett. 2005, 5, 1824-1829. doi:10.1021/n1050925i

33. Ali, M.; Yameen, B.; Neumann, R.; Ensinger, W.; Knoll, W.; Azzaroni, O. J. Am. Chem. Soc. 2008, 130, 16351-16357. doi:10.1021/ja8071258

34. Chtanko, N.; Toimil-Molares, M. E.; Cornelius, T. W.; Dobrev, D.; Neumann, R. J. Phys. Chem. B 2004, 108, 9950-9954. doi:10.1021/jp031368w

35. Toimil-Molares, M. E.; Chtanko, N.; Cornelius, T. W.; Dobrev, D.; Enculescu, I.; Blick, R. H.; Neumann, R. Nanotechnology 2004, 15, S201. doi:10.1088/0957-4484/15/4/015

36. Enculescu, I.; Toimil-Molares, M. E.; Zet, C.; Daub, M.; Westerberg, L.; Neumann, R.; Spohr, R. Appl. Phys. A 2007, 86, 43-48. doi:10.1007/s00339-006-3738-2

37. Fischer, B. E.; Metzger, S. MRS Bull. 2000, 25 (2), 39-42.

38. Trautmann, C.; Bouffard, S.; Spohr, R. Nucl. Instrum. Methods Phys. Res., Sect. B 1996, 116, 429-433. doi:10.1016/0168-583X(96)00083-3

39. Fleischer, R. L.; Price, P. B.; Walker, R. M. Nuclear tracks in solids; University of California Press: Berkeley, 1975.

40. De Sorbo, W. Nucl. Tracks 1979, 3, 13-32. doi:10.1016/0191-278X(79)90026-X

41. Ferain, E.; Legras, R. Nucl. Instrum. Methods Phys. Res., Sect. B 1993, 82, 539-548. doi:10.1016/0168-583X(93)96008-Z

42. Apel, P. Y.; Blonskaya, I. V.; Dmitriev, S. N.; Orelovitch, O. R.; Presz, A.; Sartowska, B. A. Nanotechnology 2007, 18, 305302. doi:10.1088/0957-4484/18/30/305302

43. Zhang, H.-Q.; Akram, N.; Skog, P.; Soroka, I. L.; Trautmann, C.; Schuch, R. Phys. Rev. Lett. 2012, 108, 193202. doi:10.1103/PhysRevLett.108.193202

44. Healy, K.; Schiedt, B.; Morrison, A. P. Nanomedicine 2007, 2, 875-897. doi:10.2217/17435889.2.6.875

45. Cornelius, T. W.; Apel, P. Y.; Schiedt, B.; Trautmann, C.; Toimil-Molares, M. E.; Karim, S.; Neumann, R. Nucl. Instrum. Methods Phys. Res., Sect. B 2007, 265, 553-557. doi:10.1016/j.nimb.2007.10.004

46. Apel, P. Y.; Korchev, Y. E.; Siwy, Z.; Spohr, R.; Yoshida, M. Nucl. Instrum. Methods Phys. Res., Sect. B 2001, 184, 337-346. doi:10.1016/S0168-583X(01)00722-4
47. Karim, S. Fabrication and characterization of gold nanowires. Ph.D. Thesis, University of Marburg, Germany, 2007.

48. Siwy, Z.; Apel, P.; Dobrev, D.; Neumann, R.; Spohr, R.; Trautmann, C.; Voss, K. Nucl. Instrum. Methods Phys. Res., Sect. B 2003, 208, 143-148. doi:10.1016/S0168-583X(03)00884-X

49. Apel, P. Y.; Blonskaya, I. V.; Orelovitch, O. L.; Ramirez, P.; Sartowska, B. A. Nanotechnology 2011, 22, 175302-175314. doi:10.1088/0957-4484/22/17/175302

50. Chtanko, N.; Toimil-Molares, M. E.; Cornelius, T. W.; Dobrev, D.; Neumann, R. Nucl. Instrum. Methods Phys. Res., Sect. B 2005, 236, 103-108. doi:10.1016/j.nimb.2005.03.264

51. Cornelius, T. W. Fabrication and characterisation of bismuth nanowires. Ph.D. Thesis, University of Heidelberg, Germany, 2006.

52. Toimil-Molares, M. E.; Buschmann, V.; Dobrev, D.; Neumann, R.; Scholz, R.; Schuchert, I. U.; Vetter, J. Adv. Mater. 2001, 13, 62-65. doi:10.1002/1521-4095(200101)13:1<62::AID-ADMA62>3.0.CO;2-7

53. Liu, J.; Duan, J. L.; Toimil-Molares, M. E.; Karim, S.; Cornelius, T. W.; Dobrev, D.; Yao, H. J.; Sun, Y. M.; Hou, M. D.; Mo, D.; Wang, Z. G.; Neumann, R. Nanotechnology 2006, 17, 1922-1926. doi:10.1088/0957-4484/17/8/020

54. Karim, S.; Toimil-Molares, M. E.; Maurer, F.; Miehe, G.; Ensinger, W.; Liu, J.; Cornelius, T. W.; Neumann, R. Appl. Phys. A 2006, 84, 403-407. doi:10.1007/s00339-006-3645-6

55. Rauber, M.; Brotz, J.; Duan, J.; Liu, J.; Müller, S.; Neumann, R.; Picht, O.; Toimil-Molares, M. E.; Ensinger, W. J. Phys. Chem. C 2010, 114, 22502-22507. doi:10.1021/jp108889c

56. Cornelius, T. W.; Brötz, J.; Chtanko, N.; Dobrev, D.; Miehe, G.; Neumann, R.; Toimil-Molares, M. E. Nanotechnology 2005, 16, S246-S249. doi:10.1088/0957-4484/16/5/020

57. Daub, M.; Enculescu, I.; Neumann, R; Spohr, R. J. Optoelectron. Adv. Mater. 2005, 7, 865-870.

58. Picht, O.; Müller, S.; Alber, I.; Rauber, M.; Lensch-Falk, J.; Medlin, D. L.; Neumann, R.; Toimil-Molares, M. E. J. Phys. Chem. C 2012, 116, 5367-5375. doi:10.1021/jp210491g

59. Schuchert, I. U.; Toimil-Molares, M. E.; Dobrev, D.; Vetter, J.; Neumann, R.; Martin, M. J. Electrochem. Soc. 2003, 150, C189-C194. doi:10.1149/1.1554722

60. Mueller, S.; Schotz, C.; Picht, O.; Sigle, W.; Kopold, P.; Rauber, M.; Alber, I.; Neumann, R.; Toimil-Molares, M. E. Cryst. Growth Des. 2012, 12, 615-621. doi:10.1021/cg200685c

61. Budevski, E.; Staikov, G.; Lorenz, W. J. Electrochemical Phase Formation and Growth; VCH: Weinheim, Germany, 1996. doi:10.1002/9783527614936

62. Steinhögl, W.; Schindler, G.; Steinlesberger, G.; Traving, M.; Engelhardt, M. J. Appl. Phys. 2005, 97, 023706-023712. doi:10.1063/1.1834982

63. Li, D.; Wu, Y.; Fan, R.; Yang, P.; Majumdar, A. Appl. Phys. Lett. 2003, 83, 3186-3188. doi:10.1063/1.1619221

64. Fert, A.; Piraux, L. J. Magn. Magn. Mater. 1999, 200, 338-358. doi:10.1016/S0304-8853(99)00375-3

65. Halas, N. J.; Lal, S.; Chang, W.-S.; Link, S.; Nordlander, P. Chem. Rev. 2011, 111, 3913-3961. doi:10.1021/cr200061k

66. Kreibig, U.; Vollmer, M. In Optical Properties of Metal Clusters; Toennies, J. P., Ed.; Springer Series in Materials Science, Vol. 25; Springer: Berlin, Heidelberg, 1995.

67. Valenzuela, K.; Raghavan, S.; Deymier, P. A.; Hoying, J. J. Nanosci. Nanotechnol. 2008, 8, 3416-3421. doi:10.1166/jnn.2008.122

68. Kim, C.; Gu, W.; Briceno, M.; Robertson, I. M.; Choi, H.; Kim, K. Adv. Mater. 2008, 20, 1859-1863. doi:10.1002/adma.200701460 
69. Rathmell, A. R.; Bergin, S. M.; Hua, Y.-L.; Li, Z.-Y.; Wiley, B. J. Adv. Mater. 2010, 22, 3558-3563. doi:10.1002/adma.201000775

70. Datta, M. IBM J. Res. Dev. 1998, 42, 563-566. doi:10.1147/rd.425.0563

71. Toimil-Molares, M. E.; Brötz, J.; Buschmann, V.; Dobrev, D.; Neumann, R.; Scholz, R.; Schuchert, I. U.; Trautmann, C.; Vetter, J. Nucl. Instrum. Methods Phys. Res., Sect. B 2001, 185, 192-197. doi:10.1016/S0168-583X(01)00755-8

72. Duan, J.; Liu, J.; Mo, D.; Yao, H.; Maaz, K.; Chen, Y.; Sun, Y.; Hou, M.; Qu, X.; Zhang, L.; Chen, Y. Nanotechnology 2010, 21, 365605. doi:10.1088/0957-4484/21/36/365605

73. Dobrev, D.; Vetter, J.; Angert, N.; Neumann, R. Appl. Phys. A 1999, 69, 233-237. doi:10.1007/s003390050995

74. Leopold, S.; Schuchert, I. U.; Lu, J.; Toimil-Molares, M. E.; Herranen, M.; Carlsson, J.-O. Electrochim. Acta 2002, 47, 4393-4397. doi:10.1016/S0013-4686(02)00515-7

75. Gottstein, G. Physikalische Grundlagen der Materialkunde; Springer: Berlin, 1998.

76. Zhong, S.; Koch, T.; Wang, M.; Scherer, T.; Walheim, S.; Hahn, H.; Schimmel, T. Small 2009, 5, 2265-2270. doi:10.1002/smll.200900746

77. Kelly, K. L.; Coronado, E.; Zhao, L. L.; Schatz, G. C. J. Phys. Chem. B 2003, 107, 668-677. doi:10.1021/jp026731y

78. Yi, G.; Schwarzacher, W. Appl. Phys. Lett. 1999, 74, 1746-1748. doi:10.1063/1.123675

79. Ohgai, T.; Gravier, L.; Hoffer, X.; Lindeberg, M.; Hjort, K.; Spohr, R.; Ansermet, J. P. J. Phys. D: Appl. Phys. 2003, 36, 3109-3114. doi:10.1088/0022-3727/36/24/003

80. Song, S.; Bohuslav, G.; Capitano, A.; Du, J.; Taniguchi, K.; Cai, Z.; Sun, L. J. Appl. Phys. 2012, 111, 056103. doi:10.1063/1.3692068

81. Lin, Y.-M.; Sun, X.; Dresselhaus, M. S. Phys. Rev. B 2000, 62, 4610-4623. doi:10.1103/PhysRevB.62.4610

82. Lin, Y.-M.; Cronin, S. B.; Ying, J. Y.; Dresselhaus, M. S.; Heremans, J. P. Appl. Phys. Lett. 2000, 76, 3944-3946. doi:10.1063/1.126829

83. Edelman, V. S. Adv. Phys. 1976, 25, 555-613. doi:10.1080/00018737600101452

84. Garcia, N.; Kao, Y. H.; Strongin, M. Phys. Rev. B 1972, 5, 2029-2039. doi:10.1103/PhysRevB.5.2029

85. Hicks, L. D.; Dresselhaus, M. S. Phys. Rev. B 1993, 47, 12727-12731. doi:10.1103/PhysRevB.47.12727

86. Sommerlatte, J.; Nielsch, K.; Bottner, H. Physik Journal 2007, 6 (5), 35-41.

87. Hochbaum, A. I.; Chen, R.; Diaz Delgado, R.; Liang, W.; Garnett, E. C.; Najarian, M.; Majumdar, A.; Yang, P. Nature 2008, 451, 163-167. doi:10.1038/nature06381

88. Boukai, A. I.; Bunimovich, Y.; Tahir-Kheli, J.; Yu, J.-K.; Goddard, W. A., III; Heath, J. R. Nature 2008, 451, 168-171. doi:10.1038/nature06458

89. Gao, Y.; Niu, H.; Zeng, C.; Chen, Q. Chem. Phys. Lett. 2003, 367, 141-144. doi:10.1016/S0009-2614(02)01680-9

90. Heremans, J.; Thrush, C. M.; Lin, Y.-M.; Cronin, S.; Zhang, Z.; Dresselhaus, M. S.; Mansfield, J. F. Phys. Rev. B 2000, 61, 2921-2930. doi:10.1103/PhysRevB.61.2921

91. Duan, X.; Huang, Y.; Cui, Y.; Wang, J.; Lieber, C. M. Nature 2001, 409, 66-69. doi:10.1038/35051047

92. Lai, M.; Riley, J. Chem. Mater. 2006, 18, 2233-2237. doi:10.1021/cm051613j

93. Enculescu, I.; Sima, M.; Enculescu, M.; Enache, M.; Vasile, V.; Neumann, R. Opt. Mater. 2007, 30, 72-75. doi:10.1016/j.optmat.2007.01.002
94. Enculescu, I.; Matei, E.; Sima, M.; Neumann, R.; Granville, S.; Ansermet, J.-P. IEEE Trans. Magn. 2008, 44, 2678-2680. doi:10.1109/TMAG.2008.2003242

95. Sima, M.; Enculescu, I.; Trautmann, C.; Neumann, R. J. Optoelectron. Adv. Mater. 2004, 6, 121-125.

96. Enculescu, I.; Sima, M.; Enculescu, M.; Enache, M.; Ion, L.; Antohe, S.; Neumann, R. Phys. Status Solidi B 2007, 244, 1607-1611. doi:10.1002/pssb.200675109

97. Kum, M. C.; Yoo, B. Y.; Rheem, Y. W.; Bozhilov, K. N.; Chen, W.; Mulchandani, A.; Myung, N. V. Nanotechnology 2008, 19, 325711. doi:10.1088/0957-4484/19/32/325711

98. Matei, E.; Ion, L.; Antohe, S.; Neumann, R.; Enculescu, I. Nanotechnology 2010, 21, 105202. doi:10.1088/0957-4484/21/10/105202

99. Mo, D.; Liu, J.; Yao, H. J.; Duan, J. L.; Hou, M. D.; Sun, Y. M.; Chen, Y. F.; Xue, Z. H.; Zhang, L. J. Cryst. Growth 2008, 310, 612-616. doi:10.1016/j.jcrysgro.2007.11.034

100. Mallet, J.; Molinari, M.; Martineau, F.; Delavoie, F.; Fricoteaux, P.; Troyon, M. Nano Lett. 2008, 8, 3468-3474. doi:10.1021/nl802352e

101.Al-Salman, R.; Mallet, J.; Molinari, M.; Fricoteaux, P.; Martineau, F.; Troyon, M.; Zein El Abedin, S.; Endres, F. Phys. Chem. Chem. Phys. 2008, 10, 6233-6237. doi:10.1039/b809075k

102. Endres, F. ChemPhysChem 2002, 3, 144-154. doi:10.1002/1439-7641(20020215)3:2<144::AID-CPHC144>3.0.CO;2\#

103.Jeong, S.; Garnett, E. C.; Wang, S.; Yu, Z.; Fan, S.; Brongersma, M. L.; McGehee, M. D.; Cui, Y. Nano Lett. 2012, 12 , 2971-2976. doi:10.1021/nl300713x

104.Kline, T. R.; Tian, M.; Wang, J.; Sen, A.; Chan, M. W. H.; Mallouk, T. E. Inorg. Chem. 2006, 45, 7555-7565. doi:10.1021/ic0601384

105.Paxton, W. F.; Kistler, K. C.; Olmeda, C. C.; Sen, A.; St. Angelo, S. K.; Cao, Y.; Mallouk, T. E.; Lammert, P. E.; Crespi, V. H. J. Am. Chem. Soc. 2004, 126, 13424-13431. doi:10.1021/ja047697z

106. Nicewarner-Peña, S. R.; Freeman, R. G.; Reiss, B. D.; He, L.; Peña, D. J.; Walton, I. D.; Cromer, R.; Keating, C. D.; Natan, M. J. Science 2001, 294, 137-141. doi:10.1126/science.294.5540.137

107.Piraux, L.; George, J. M.; Despres, J. F.; Leroy, C.; Ferain, E.; Legras, R.; Ounadjela, K.; Fert, A. Appl. Phys. Lett. 1994, 65, 2484-2486. doi:10.1063/1.112672

108. Blondel, A.; Meier, J. P.; Doudin, B.; Ansermet, J.-P. Appl. Phys. Lett. 1994, 65, 3019-3021. doi:10.1063/1.112495

109.Schwarzacher, W.; Attenborough, K.; Michel, A.; Nabiyouni, G.; Meier, J. P. J. Magn. Magn. Mater. 1997, 165, 23-29. doi:10.1016/S0304-8853(96)00465-9

110.Matei, E.; Preda, N.; Enculescu, M.; Ansermet, J.-P.; Toimil-Molares, M. E.; Enculescu, I.

Digest Journal of Nanomaterials and Biostructures 2010, 5 , 1067-1076.

111. Krieg, J. Bachelor Thesis, Faculty of Physics, Technische Universität Darmstadt, 2010.

112.Zhu, J.; Yu, Z.; Burkhard, G. F.; Hsu, C.-M.; Connor, S. T.; Xu, Y.; Wang, Q.; McGehee, M.; Fan, S.; Cui, Y. Nano Lett. 2009, 9 , 279-282. doi:10.1021/nl802886y

113. Maurer, F.; Dangwal, A.; Lysenkov, D.; Müller, G.; Toimil-Molares, M. E.; Trautmann, C.; Brötz, J.; Fuess, H. Nucl. Instrum. Methods Phys. Res., Sect. B 2006, 245, 337-341. doi:10.1016/j.nimb.2005.11.124 
114.Serbun, P.; Jordan, F.; Navitski, A.; Müller, G.; Alber, I.; Toimil-Molares, M. E.; Trautmann, C. Eur. Phys. J.: Appl. Phys. 2012, 58, 10402. doi:10.1051/epjap/2012110473

115.Serbun, P.; Jordan, F.; Navitski, A.; Müller, G.; Alber, I.; Toimil-Molares, M. E.; Trautmann, C. Field emission proporties of copper nanocones grown in polymer ion-track membranes. In Proceedings of 24th International Vacuum Nanoelectronics Conference (IVNC), 2011, Wuppertal, Germany, July 18-22, 2011; pp 183-184.

116. Lysenkov, D.; Müller, G. Int. J. Nanotechnol. 2005, 2, 239-254. doi:10.1504/IJNT.2005.008062

117.Serbun, P.; Jordan, F.; Navitski, A.; Müller, G.; Alber, I.; Toimil-Molares, M. E.; Trautmann, C. GSI Scientific Report 2011, 432.

118.Wang, M. C. P.; Gates, B. D. Mater. Today 2009, 12, 34-43. doi:10.1016/S1369-7021(09)70158-0

119.Lindeberg, M.; Hjort, K. Sens. Actuators, A 2003, 105, 150-161. doi:10.1016/S0924-4247(03)00088-8

120.Rauber, M.; Alber, I.; Müller, S.; Neumann, R.; Picht, O.; Roth, C.; Schökel, A.; Toimil-Molares, M. E.; Ensinger, W. Nano Lett. 2011, 11, 2304-2310. doi:10.1021/nl2005516

121.Weber-Bargioni, A.; Schwartzberg, A.; Schmidt, M.; Harteneck, B.; Ogletree, D. F.; Schuck, P. J.; Cabrini, S. Nanotechnology 2010, 21, 065306. doi:10.1088/0957-4484/21/6/065306

122.Chen, X.; Guo, Z.; Yang, G.-M.; Li, J.; Li, M.-Q.; Liu, J.-H.; Huang, X.-J. Mater. Today 2011, 13, 28-41. doi:10.1016/S1369-7021(10)70201-7

123. Taychatanapat, T.; Bolotin, K. I.; Kuemmeth, F.; Ralph, D. C. Nano Lett. 2007, 7, 652-656. doi:10.1021/nl062631i

124.Weber, D.; Katzmann, J.; Neubrech, F.; Härtling, T.; Pucci, A. Opt. Mater. Express 2011, 1, 1301-1306. doi:10.1364/OME.1.001301

125. Qin, L.; Park, S.; Huang, L.; Mirkin, C. A. Science 2005, 309, 113-115. doi:10.1126/science. 1112666

126.Alber, I.; Sigle, W.; Müller, S.; Neumann, R.; Picht, O.; Rauber, M.; van Aken, P. A.; Toimil-Molares, M. E. ACS Nano 2011, 5, 9845-9853. doi:10.1021/nn2035044

127.Alber, I.; Müller, S.; Picht, O.; Rauber, M.; Toimil-Molares, M. E.; Neumann, R. GSI Scientific Report 2010, 398.

128. Mayadas, A. F.; Shatzkes, M. Phys. Rev. B 1970, 1, 1382-1389. doi:10.1103/PhysRevB.1.1382

129. Dingle, R. B. Proc. R. Soc. London, Ser. A 1950, 201, 545-560. doi:10.1098/rspa.1950.0077

130.Toimil-Molares, M. E.; Hoehberger, E. M.; Schaeflein, C.; Blick, R. H.; Neumann, R.; Trautmann, C. Appl. Phys. Lett. 2003, 82, 2139-2141. doi:10.1063/1.1563741

131. Katzenmeyer, A. M.; Léonard, F.; Talin, A. A.; Toimil-Molares, M. E.; Cederberg, J. G.; Huang, J. Y.; Lensch-Falk, J. L. IEEE Trans. Nanotechnol. 2010, 10, 92-95. doi:10.1109/TNANO.2010.2062198

132.Talin, A. A.; Léonard, F.; Katzenmeyer, A. M.; Swartzentruber, B. S.; Picraux, S. T.; Toimil-Molares, M. E.; Cederberg, J. G.; Wang, X.; Hersee, S. D.; Rishinaramangalum, A. Semicond. Sci. Technol. 2010, 25, 024015. doi:10.1088/0268-1242/25/2/024015

133. Cornelius, T. W.; Toimil-Molares, M. E.; Neumann, R.; Karim, S. J. Appl. Phys. 2006, 100, 114307. doi:10.1063/1.2388857

134.Cornelius, T. W.; Toimil-Molares, M. E.; Karim, S.; Neumann, R. Phys. Rev. B 2008, 77, 125425. doi:10.1103/PhysRevB.77.125425

135. Karim, S.; Ensinger, W.; Cornelius, T. W.; Neumann, R. Physica E 2008, 40, 3173-3178. doi:10.1016/j.physe.2008.05.011
136. Cornelius, T. W.; Picht, O.; Müller, S.; Neumann, R.; Völklein, F.; Karim, S.; Duan, J. L. J. Appl. Phys. 2008, 103, 103713. doi:10.1063/1.2927443

137. Cornelius, T. W.; Toimil-Molares, M. E.; Neumann, R.; Fahsold, G.; Lovrincic, R.; Pucci, A.; Karim, S. Appl. Phys. Lett. 2006, 88, 103114. doi:10.1063/1.2183823

138. Neubrech, F.; Kolb, T.; Lovrincic, R.; Fahsold, G.; Pucci, A.; Aizpurua, J.; Cornelius, T. W.; Toimil-Molares, M. E.; Neumann, R.; Karim, S. Appl. Phys. Lett. 2006, 89, 253104. doi:10.1063/1.2405873

139. Neubrech, F.; Pucci, A.; Cornelius, T. W.; Karim, S.; Garcia-Etxarri, A.; Aizpurua, J. Phys. Rev. Lett. 2008, 101, 157403. doi:10.1103/PhysRevLett.101.157403

140.Glaeser, A. M. Interface Sci. 2001, 9, 65-82. doi:10.1023/A:1011279015039

141.Li, H.; Biser, J. M.; Perkins, J. T.; Dutta, S.; Vinci, R. P.; Chan, H. M. J. Appl. Phys. 2008, 103, 024315. doi:10.1063/1.2837053

142. Klinger, L.; Rabkin, E. Acta Mater. 2006, 54, 305-311. doi:10.1016/j.actamat.2005.08.034

143. Cahn, J. W. Scr. Metall. 1979, 13, 1069-1071. doi:10.1016/0036-9748(79)90205-9

144.Gurski, K. F.; McFadden, G. B. Proc. R. Soc. London, Ser. A 2003, 459, 2575-2598. doi:10.1098/rspa.2003.1144 And references therein.

145.Plateau, J. Smithsonian Institution, Annual Report 1873, 1863.

146. Lord Rayleigh. Proc. London Math. Soc. 1878, 10, 4-13. doi:10.1112/plms/s1-10.1.4

147. Nichols, F. A.; Mullins, W. W. Trans. Metall. Soc. AIME 1965, 233, 1840-1845

148. Toimil-Molares, M. E.; Balogh, A. G.; Cornelius, T. W.; Neumann, R.; Trautmann, C. Appl. Phys. Lett. 2004, 85, 5337-5339. doi:10.1063/1.1826237

149. Karim, S.; Toimil-Molares, M. E.; Balogh, A. G.; Ensinger, W.; Cornelius, T. W.; Khan, E. U.; Neumann, R. Nanotechnology 2006, 17, 5954-5959. doi:10.1088/0957-4484/17/24/009

150.Karim, S.; Toimil-Molares, M. E.; Ensinger, W.; Balogh, A. G.; Cornelius, T. W.; Khan, E. U.; Neumann, R. J. Phys. D: Appl. Phys. 2007, 40, 3767-3770. doi:10.1088/0022-3727/40/12/031

151.Zhou, Z. F.; Pan, Y.; Zhou, Y. C.; Yang, L. Appl. Surf. Sci. 2011, 257, 9991-9995. doi:10.1016/j.apsusc.2011.06.125

152. Toimil-Molares, M. E.; Röntzsch, L.; Sigle, W.; Heinig, K.-H.; Trautmann, C.; Neumann, R. Adv. Funct. Mater. 2012, 22, 695-701. doi:10.1002/adfm.201102260 


\section{License and Terms}

This is an Open Access article under the terms of the Creative Commons Attribution License

(http://creativecommons.org/licenses/by/2.0), which permits unrestricted use, distribution, and reproduction in any medium, provided the original work is properly cited.

The license is subject to the Beilstein Journal of Nanotechnology terms and conditions:

(http://www.beilstein-journals.org/bjnano)

The definitive version of this article is the electronic one which can be found at:

doi:10.3762/bjnano.3.97 